\title{
Fast gas heating in nitrogen-oxygen discharge plasma. II. Energy exchange in the afterglow of a volume nanosecond discharge at moderate pressures.
}

\author{
E.I. Mintoussov ${ }^{1}$, S.J. Pendleton ${ }^{2}$, F. Gerbault ${ }^{3}$, N.A. Popov ${ }^{4}$, \\ $\underline{\text { S.M. Starikovskaia }}{ }^{1}$ \\ ${ }^{1}$ Laboratoire de Physique des Plasmas, Ecole Polytechnique, Route de Saclay, 91128 \\ Palaiseau Cedex, France \\ ${ }^{2}$ Department of Physics and Astronomy, University of Southern California, Los \\ Angeles, USA \\ ${ }^{3}$ Ecole Polytechnique de l'Université d'Orléans, France \\ ${ }^{4}$ Skobeltsyn Institute of Nuclear Physics, Moscow State University, Moscow, Russia \\ E-mail: svetlana.starikovskaya@lpp.polytechnique.fr
}

\begin{abstract}
The process of fast gas heating in air in the near afterglow of a pulsed nanosecond spatially uniform discharge has been investigated experimentally and numerically at moderate (3-9 mbar) pressures and high (200-400 Td) reduced electric fields. The temporal behavior of discharge current, deposited energy, electric field and temperature were measured. The role of processes with participation of excited and charged species was analyzed. It was shown that under the considered conditions the main energy release takes place in reactions of nitrogen and oxygen dissociation by electron impact and quenching of electronically excited nitrogen molecules, such as $\mathrm{N}_{2}\left(\mathrm{~A}^{3} \Sigma_{u}^{+}, \mathrm{B}^{3} \Pi_{g}, \mathrm{C}^{3} \Pi_{u}, \mathrm{a}^{1} \Sigma_{u}^{-}\right)$by oxygen and quenching of excited $\mathrm{O}\left({ }^{1} \mathrm{D}\right)$ atoms by $\mathrm{N}_{2}$. It was shown that about $24 \%$ of the discharge energy goes to fast gas heating during first tens of microseconds after the discharge.
\end{abstract}




\section{Introduction}

So-called fast gas heating, which is the energy release in the discharge or post-discharge due to the relaxation of energy stored in electronic degrees of freedom and in ionization, has been investigated for decades. A kinetic mechanism describing fast gas heating has been suggested and verified [1] for pulsed discharges in air of duration $100 \mu \mathrm{s}$ and more, current densities of $0.1-10 \mathrm{~A} / \mathrm{cm}^{2}$, reduced electric fields less than $100 \mathrm{Td}$, gas pressures of $0.4-6$ Torr.

During the few last years, renewed interest in fast energy transfer from electronic degrees of freedom to gas heating is explained by plasma applications for combustion initiation [2] and flow control [3]-[5]. Indeed, to initiate the combustion process, it is necessary to provide an efficient dissociation and production of radicals, but it is also important to heat the gas as fast as possible to allow the chain reaction development $[6,7]$. For plasma assisted aerodynamics, the efficiency of a concentrated heat release resulting in shock waves [4] or vortex [5] formation to rearrange the flow near the surface has been demonstrated by various authors.

The experimental evidence of a fast energy release has been demonstrated experimentally in the near afterglow of nanosecond pulsed discharges at atmospheric pressure $[4,8,9]$. It should be noted that nanosecond discharges, due to their significant overvoltage on the electrodes and short duration, may provide significant (hundreds of Td) electric fields, where the main part of discharge energy goes to excitation of electronic degrees of freedom (see, for example, analysis in [10]). Reduced electric fields, reported for surface nanosecond discharge, may be even higher and reach values up to $\mathrm{kTd}[4,11]$.

It has been shown [4] that significant gas heating in surface nanosecond dielectric barrier discharge (DBD) in asymmetric plasma actuator geometry takes place approximately $1 \mu \mathrm{s}$ after the nanosecond pulse is applied. From the velocity of shock wave propagation the authors obtained values for gas temperature of 70,200 , and $400 \mathrm{~K}$ in the plasma layer for 7, 12, and 50 ns pulse durations, respectively (voltage amplitudes ranged from $10-50 \mathrm{kV}$ ). The emerging shock wave together with the secondary vortex flows disturbed the main flow and caused flow rearrangement. Measurements of gas temperature using nitrogen emission gave values up to $400 \mathrm{~K}$ for pulse duration $25 \mathrm{~ns}$ at time $t=1 \mu \mathrm{s}$.

Paper [8] gives measurements of temperature dynamics under gas excitation by a pulsed discharge in atmospheric pressure air preheated to $1000 \mathrm{~K}$ and flowing at 0.5$2.6 \mathrm{~m} / \mathrm{s}$. The pulse duration was $30 \mathrm{~ns}$, the pulse amplitude did not exceed $6-8.5 \mathrm{kV}$, and the discharge was initiated in pin-to-pin geometry with the interelectode space being equal to $5 \mathrm{~mm}$ with a frequency of $30 \mathrm{kHz}$. The gas temperature was determined using measured emission of $\mathrm{N}_{2}\left(\mathrm{C}^{3} \Pi_{u}, v^{\prime}=0\right) \rightarrow \mathrm{N}_{2}\left(\mathrm{~B}^{3} \Pi_{g}, v^{\prime \prime}=0\right)$ transition. The authors report the gas temperature increase by several thousand Kelvin in the span of about 15-20 ns after the application of the high-voltage pulse. It should be noted that the highest temperature values obtained in the experiments [8] correspond to the near 
afterglow phase, when additional non-direct processes of $\mathrm{N}_{2}\left(\mathrm{C}^{3} \Pi_{u}, v^{\prime}=0\right)$ population may influence rotational distribution of the upper state, and, consequently, the obtained temperature value.

The gas density decrease in the near afterglow of a pulsed positive streamer in air in pin-to-plate geometry at $13 \mathrm{~mm}$ between the electrodes was studied in dry and humid air [9] by means of time-resolved shadography combined with optical emission. The authors demonstrated that the gas density decreases in two steps. The first, fast step, in the author's opinion, is connected with gas heating owing to electron impact onto molecules, and the second step is explained by vibrational-translational (VT) energy transfer.

A few mechanisms describing fast gas heating in nitrogen-oxygen mixtures have been recently suggested $[12,13]$. Paper [12] gives detailed numerical analysis of the comparative roles of different processes for a field range of 50-400 $\mathrm{Td}$ for gas pressure equal to $1 \mathrm{~atm}$ without comparison with experiments. Only paper [13] presents analysis of experiments [14], where shock wave propagation through air at $P \approx 20$ Torr preliminary excited by a volume nanosecond discharge has been studied, and results of experiments in a surface nanosecond dielectric barrier discharge (SDBD) in air at atmospheric pressure have been presented together with a computational model. To explain high values of temperature increase at a given energy input, the authors [13] suggest that at high electric fields and high pressures all the energy released in ionmolecular reactions and in ion-ion recombination is spent on gas heating and leads to significant temperature increase. The scale of fast gas heating in very high electric fields $(600-1000 \mathrm{Td})$ is reported and demonstrates a good coincidence between the experiments and the model. Still, work [13] leaves a few questions connected with the complexity of experiments at high $E / N$; it is, for example, the accuracy of measurements of specific deposited energy for spatially non-uniform SDBD discharge at high pressure.

Thus, the mechanism for fast gas heating at electric fields higher than $200 \mathrm{Td}$ still remains a questionable issue and needs additional experimental and computational verification. The first part of a presented work [15] describes kinetic mechanism for a broad range of reduced electric fields and analysis of available experimental data. The aim of this part of our study is to develop an experimental approach for measuring key fast gas heating parameters and to verify a model proposed by $[1,15]$ for the range of higher electric fields.

To study the fast energy release in the afterglow of a pulsed discharge at high electric field, a high-voltage nanosecond discharge in the form of a fast ionization wave (FIW) was used. The main reasons for using FIW are the spatial uniformity of the discharge, high values of reduced electric field during the discharge development, short duration of the discharge allowing separation of the discharge action and of the relaxation process; and the fact that FIW is well studied and characterized [16, 17]. The paper reports electric current, specific energy input and reduced electric field measurements at a nanosecond time scale, combined with temperature measurements at the microsecond time scale in a spatially uniform configuration of a nanosecond discharge at moderate 
pressures. Analysis of main processes responsible for fast gas heating is given and the relative role of different processes is discussed.

\section{Experimental setup}

A discharge system has been developed that allows measurements of the current through the discharge setup, distribution of the potential along the discharge gap and emission from the discharge with nanosecond resolution, as well as measurements of the main active species responsible for kinetics in early afterglow.

The discharge is initiated in a quartz tube of $200 \mathrm{~mm}$ length with $9 \mathrm{~mm}$ inner diameter and $1 \mathrm{~mm}$ wall thickness. Semi-conical electrodes with $5 \mathrm{~mm}$ diameter axial openings are placed at the ends of the quartz tube. Traditionally, FIW experiments use flat $[16,17]$ or conical [18] electrodes to facilitate local electric field enhancement near the electrodes for discharge stabilization at low pressures. In this experiment, however, it is necessary for the electrodes to be hollow in order to allow optical probing along the longitudinal axis of the tube. For the sake of simplicity both the high and low voltage electrodes are identical in design. An Oriel deuterium lamp is used to stabilize the discharge initiation by focusing the light onto the high-voltage electrode with a UV lens. The discharge tube is surrounded by a grounded screen of $6 \mathrm{~cm}$ diameter. Two glass side tubes of $10 \mathrm{~mm}$ in diameter are connected to the electrodes (see figure 1) so that the total length of the system is equal to $78 \mathrm{~cm}$. This is to create a laser cavity for cavity ring-down spectroscopy (CRDS) measurements of $\mathrm{N}_{2}\left(\mathrm{~A}^{3} \Sigma_{u}^{+}\right)$density in the FIW afterglow. Details of the laser system and preliminary results of CRDS measurements are described in [19].

The discharge tube was pumped with a XDS5 rotary pump; gas flow in a range of $10-30 \mathrm{sccm}$ was used so that the gas was recycled between subsequent high voltage pulses. Gas pressure was varied from 1 to 15 mbar in order to check the discharge propagation in this type of a FIW system and to compare the characteristics of the discharge for regimes corresponding to different reduced electric field $(E / N)$ values. Synthetic air $\left(\mathrm{N}_{2}: \mathrm{O}_{2}=8: 2\right)$ or nitrogen with a purity of $99.999 \%$ were used for experiments.

Pulses with negative polarity, $22 \mathrm{kV}$ amplitude on the high voltage electrode, $4 \mathrm{~ns}$ rise time, and $28 \mathrm{~ns}$ FWHM were applied at $2 \mathrm{~Hz}$ frequency from a FID FPG 10-1MKS20 pulse generator through a 25-m coaxial $50 \mathrm{ohm}$ RG213 cable. The low voltage electrode was connected to a coaxial cable 100 or $200 \mathrm{~m}$ in length. Two coaxial calibrated current shunts were installed into a cable shield at a distances $12.5 \mathrm{~m}$ before and $12.5 \mathrm{~m}$ after the discharge tube. Each shunt was composed of 13 low-inductive resistors connected in parallel. A calibrated capacitive detector was installed into a slit of the screen of the discharge tube. Figure 2 represents a scheme of the experimental setup and typical signal from back current shunts (BCS).

In the present configuration of the experimental setup, three successive high-voltage pulses were observed in the system due to reflections of the pulse from the discharge 

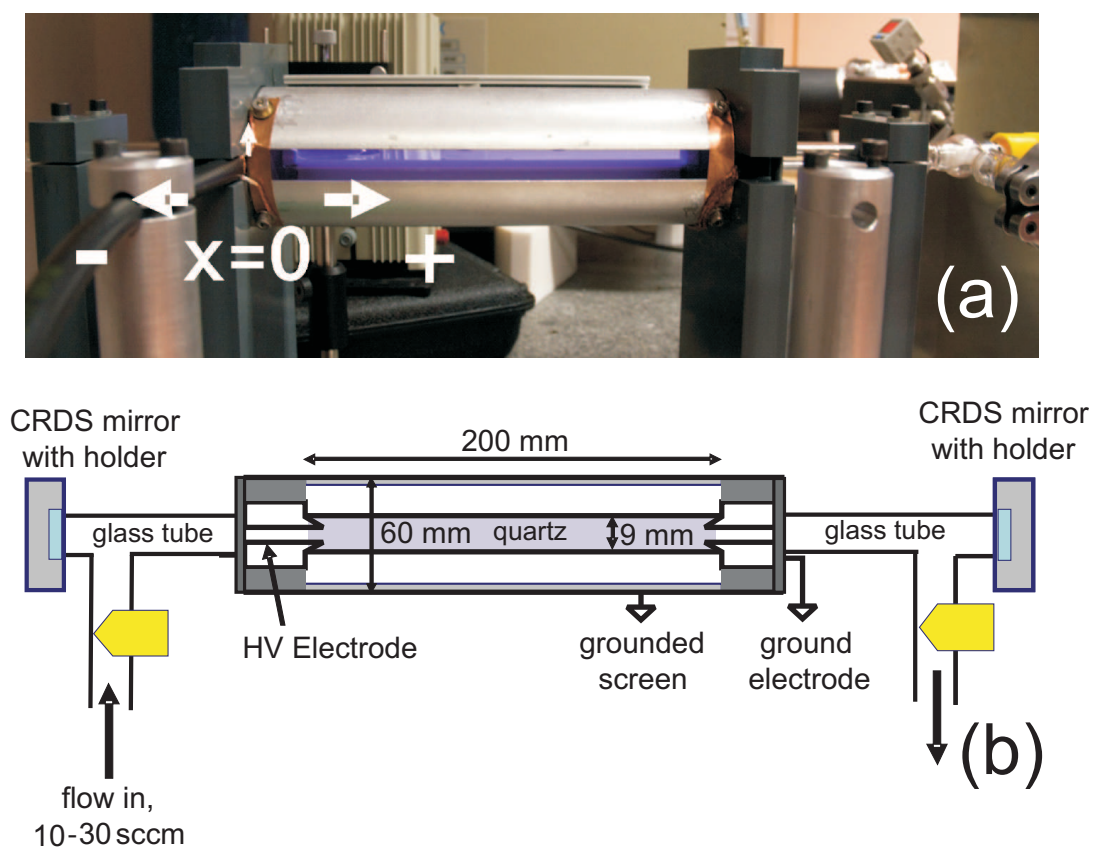

Figure 1. Photo (a) and scheme (b) of the discharge tube.

tube and then from the generator. These three pairs of pulses (incident-reflected from the discharge tube) and three correlated transmitted pulses are clearly seen in figure 2 in the time interval $0-0.7 \mu \mathrm{s}$. The time between pulses is determined by a cable length between the current shunt and/or the high voltage generator/discharge tube.

The current and energy delivered to the discharge were deduced from analysis of the incident, reflected, and transmitted pulses recorded using the current shunts and a LeCroy WR44Xi Oscilloscope with 0.5 ns resolution.

The dynamics of the potential drop along the discharge tube starting from the cathode toward the anode over distance $L=140 \mathrm{~mm}$ was measured in $5 \mathrm{~mm}$ increment by a capacitive detector. Reduced electric field vs time was derived from these measurements for different positions along the discharge tube. Details of the measurement procedure can be found elsewhere [20].

The present work is a first attempt to study parameters of a FIW in a system with hollow electrodes and side tubes. The amplitude of emission of the second positive system of molecular nitrogen $\left(\mathrm{N}_{2}\left(\mathrm{C}^{3} \Pi_{u}, v^{\prime}=0\right) \rightarrow \mathrm{N}_{2}\left(\mathrm{~B}^{3} \Pi_{g}, v^{\prime \prime}=1\right), \lambda=357.7 \mathrm{~nm}\right)$ along the discharge tube and distribution of electric potential along the tube were measured in preliminary experiments. It was found that (i) neither emission, nor electric potential is observed in the side tube connected to low-voltage electrode; (ii) strong emission and some potential drop is observed between the high-voltage and low-voltage electrodes depending upon gas pressure; (iii) some emission is observed from the side tube close to the high-voltage electrode (region $x<0$ in figure 1 ) while the electric potential in this part of the tube is always close to the potential of the high-voltage electrode. Statement (iii) was true whether a side tube without metal parts or a side 


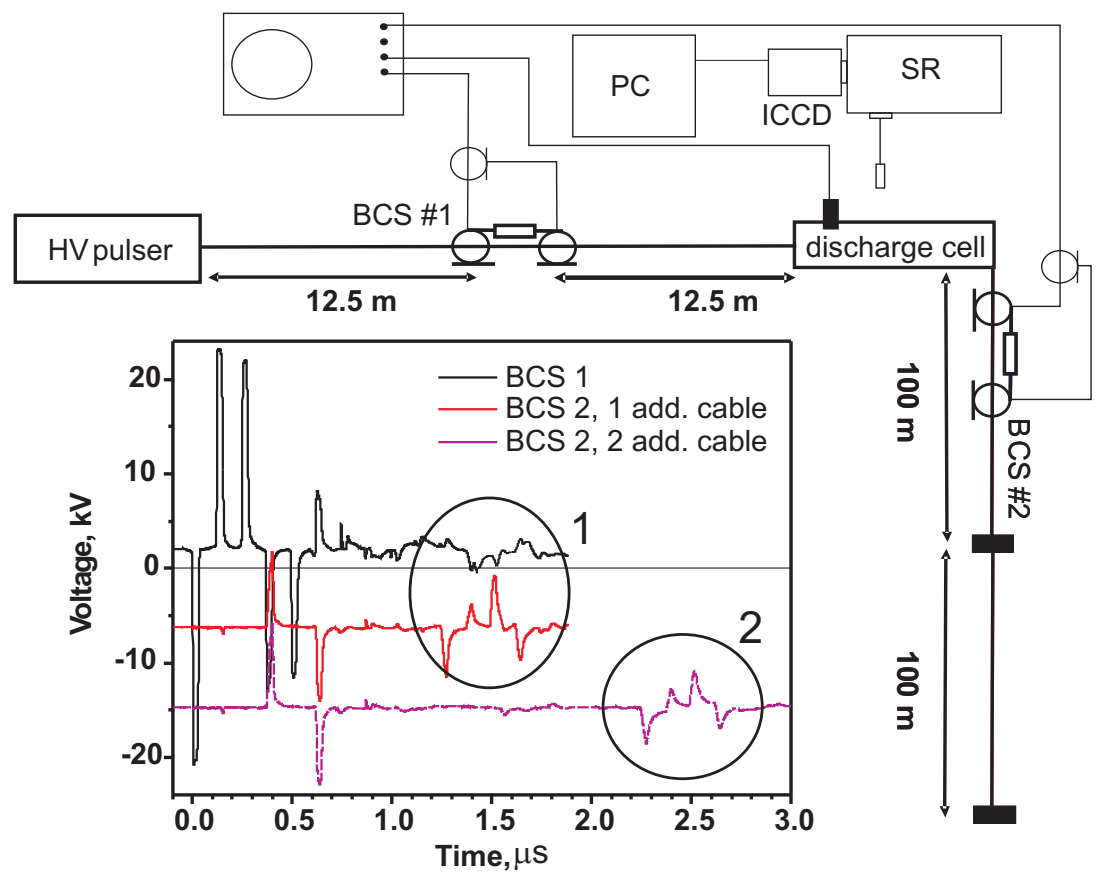

Figure 2. Scheme of the experimental setup and typical shape of signals from the back current shunts. Circles 1,2 designate additional reflections from the cable end used to excite $\mathrm{N}_{2}\left(\mathrm{C}^{3} \Pi_{u}\right)$ emission (see text for the detailed explanations).

tube with a CRDS mirror at floating potential were used.

Figure 3 presents the distribution of emission between the main discharge zone and side tube for the tube with a CRDS mirror. It is clearly seen that emission in the side tube is at least one order of magnitude less intense than in the interelectrode space. To check the energy losses, the discharge tube was disassembled and the deposited energy measured with and without a side tube adjacent to the high-voltage electrode. It was concluded that the difference in energy release in the gas for two used configurations does not exceed $10 \%$. We therefore believe that the discharge develops primarily between the two metal electrodes and the energy release in the side tubes may be neglected for the purposes of this work.

It should be noted that the discharge cell used in the present work was characterized by a somewhat complicated discharge start. The main difference compared to a traditionally used geometry are the $5 \mathrm{~mm}$ openings in the electrodes and the two side tubes. Special experiments were therefore performed to check the discharge development.

It is known that for a typical voltage amplitude of $20 \mathrm{kV}$ on the electrode in discharge tubes $2-5 \mathrm{~cm}$ in diameter and $20-60 \mathrm{~cm}$ in length, the nanosecond discharge starts with high stability for repetitive frequencies starting from a few $\mathrm{Hz}$ with flat or conical high-voltage electrodes $[17,21,20]$. The discharge develops uniformly in space within a pressure range of $1-15$ mbar, with a maximum energy input at about 4-6 mbar.

By contrast, in our case the discharge was not stable even with UV-preionization. In 


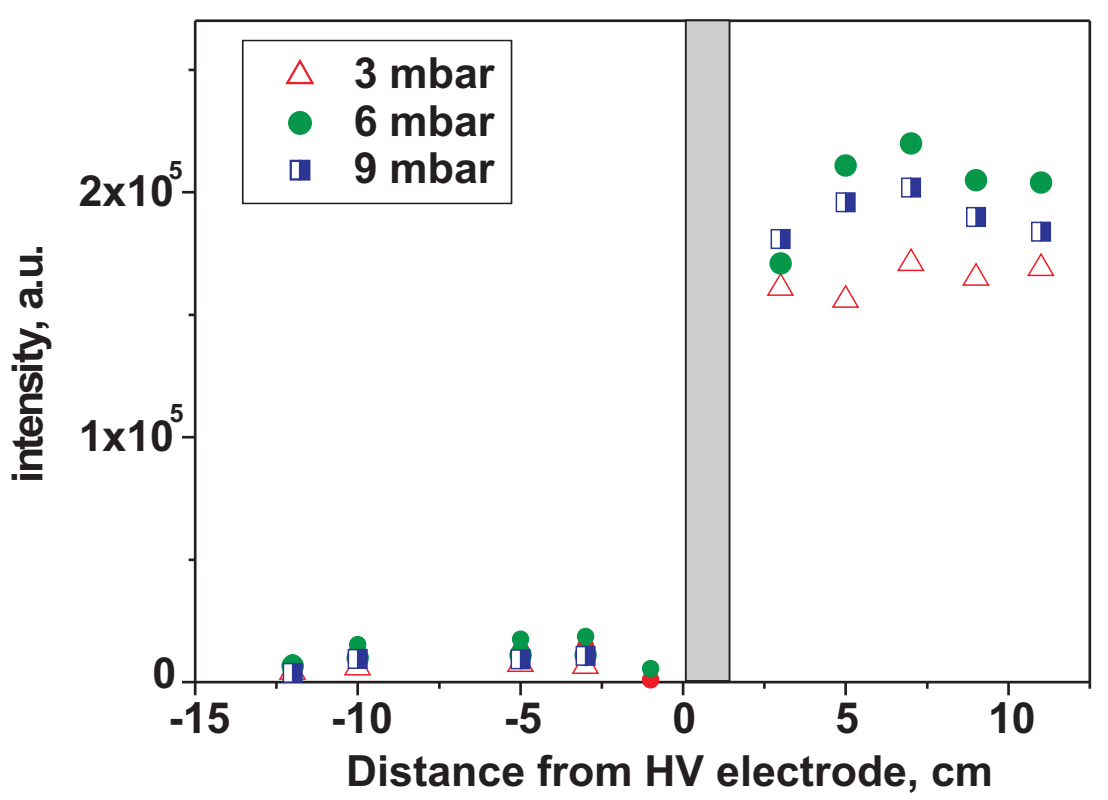

Figure 3. Analysis of discharge development. Peak emission intensity $(\lambda=357.7 \mathrm{~nm})$ between the electrodes $(x>0)$ and in the side tube $(x<0)$.

a special set of experiments to analyze the discharge stability, 100 successive oscillograms from the current shunts were taken for each regime and deposited energy was calculated. The results of statistical analysis for a pressure 9 mbar are given by figure 4 . It is clearly seen that about $70 \%$ of shots give repetitive data. Therefore for all the experiments we first made a statistical analysis, and then only the data from quasi-stationary part (events $1-70$ in the figure 4 ) were taken to provide for stability of all the parameters analyzed.

Emission spectra were measured with a UV fiber optic-fed Andor SR-303i spectrometer (grating with $2400 \mathrm{l} / \mathrm{mm}$, operating range $190-700 \mathrm{~nm}$, reverse linear dispersion $2.6 \mathrm{~nm} / \mathrm{mm}$ ) and Andor iStar DH734-18U-03 ICCD camera (spectral range $115-900 \mathrm{~nm}$ ). The spectrograph was calibrated using an Ocean Optics $\mathrm{Hg}-\mathrm{Ar}$ lamp. In order to capture the entirety of the emission, a 100 ns gate was used. The ICCD camera gate monitor and voltage pulse waveforms were measured simultaneously with the oscilloscope in order to ensure timing accuracy. Emission measurements were taken in a few time instants, so that the camera gate was synchronized either with pulses from the generator or with pulses reflected from a 100 or $200 \mathrm{~m}$ cable used as a delay line. These reflections are marked with circles 1 and 2 in figure 2, respectively. They provide the delay of emission measurements relative to the discharge within a range $1-2 \mu \mathrm{s}$.

To derive a gas temperature, the rotational spectra of the emission of the $0-1$ transition of the second positive system of $\mathrm{N}_{2}(\lambda=357.7 \mathrm{~nm})$ were measured. Specair code [22] was used to simulate spectra with the slit function determined experimentally 


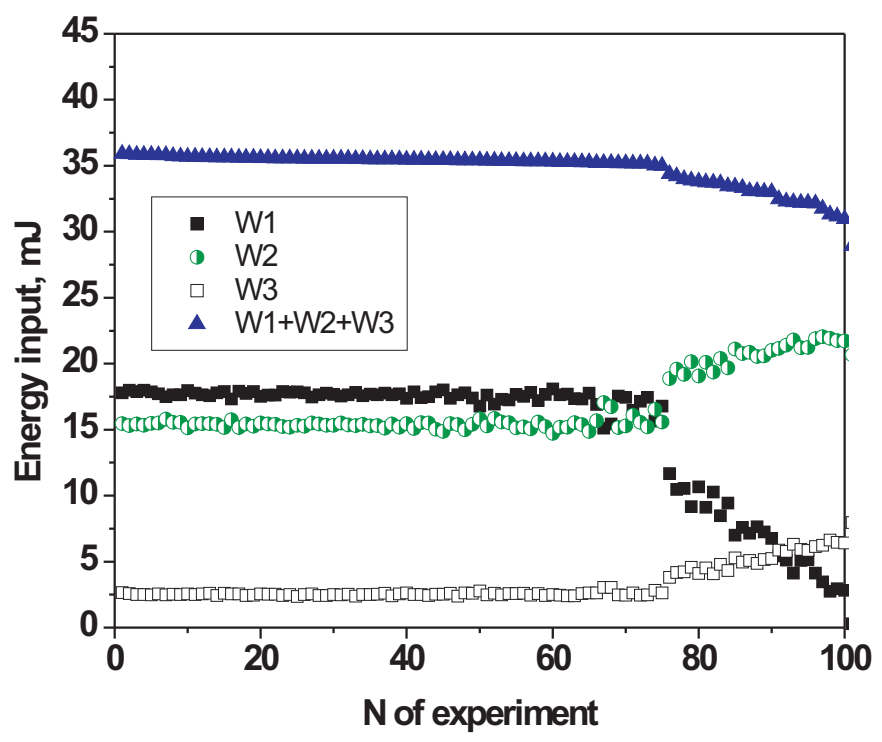

Figure 4. Statistical analysis of stability of a FIW start. Typical data obtained for $\mathrm{N}_{2}: \mathrm{O}_{2}=80: 20$ mixture, pressure 9 mbar. W1, first pair of pulses; W2, second pair of pulses; W3, third pair of pulses; W1+W2+W3, total deposited energy.

on the basis of the $\mathrm{Hg}$ line.

In the case when rotational relaxation of the electronically excited state is slow comparing to the life time, it is important that the population takes place due to direct electron impact. Under this condition, the rotational distribution of the upper electronic state reproduces the rotational distribution of the ground state. The life time of $\mathrm{N}_{2}\left(\mathrm{C}^{3} \Pi_{u}\right)$ state is about $40 \mathrm{~ns}$ [37], which is smaller than a typical time of rotational relaxation, so special experimental efforts were taken to ensure that it is possible to neglect additional stray emission caused by pooling processes $\left(\mathrm{N}_{2}\left(\mathrm{~A}^{3} \Sigma_{u}^{+}\right)+\mathrm{N}_{2}\left(\mathrm{~A}^{3} \Sigma_{u}^{+}\right)\right.$ $\left.\rightarrow \mathrm{N}_{2}\left(\mathrm{C}^{3} \Pi_{u}\right)+\mathrm{N}_{2}, \quad \mathrm{~N}_{2}\left(\mathrm{C}^{3} \Pi_{u}\right) \rightarrow \mathrm{N}_{2}\left(\mathrm{~B}^{3} \Pi_{g}\right)+h \nu\right)$.

Figure 5 gives an example of nitrogen emission at $\lambda=357.7 \mathrm{~nm}$ for two test cases. The solid line represents the emission in the additional pulse when the additional discharge is initiated $1.5 \mu \mathrm{s}$ after the first high-voltage pulse $(100 \mathrm{~m}$ cable is connected to the low-voltage electrode). The dashed line represents the emission in the same time instant when the additional pulse is absent (the $200 \mathrm{~m}$ cable is connected to the lowvoltage electrode). It is clearly seen that the background emission of the second positive system of $\mathrm{N}_{2}$ is still observed but the amplitude of the emission is orders of magnitude lower. If the temperature were determined on the basis of the background emission caused by pooling processes, it would be roughly $700 \mathrm{~K}$. Temperature, determined from the emission excited by the additional pulse, gives values about $400 \mathrm{~K}$. Thus, every time the measurements were performed in the afterglow, we checked that the background emission is significantly lower in amplitude than the emission caused by an additional 
high-voltage pulse.

\section{Experimental results}

Preliminary experiments show that under given experimental conditions the optimal pressure range for the development of a nanosecond discharge is $1-15$ mbar. For the analysis of fast gas heating, a set of experiments at 3, 6 and 9 mbar has been performed. For each pressure, electric current, deposited energy, and electric field versus time have been measured at a nanosecond time scale. Temperature was measured in 5 time instants within the time interval of $30 \mathrm{~ns}-3 \mu \mathrm{s}$.

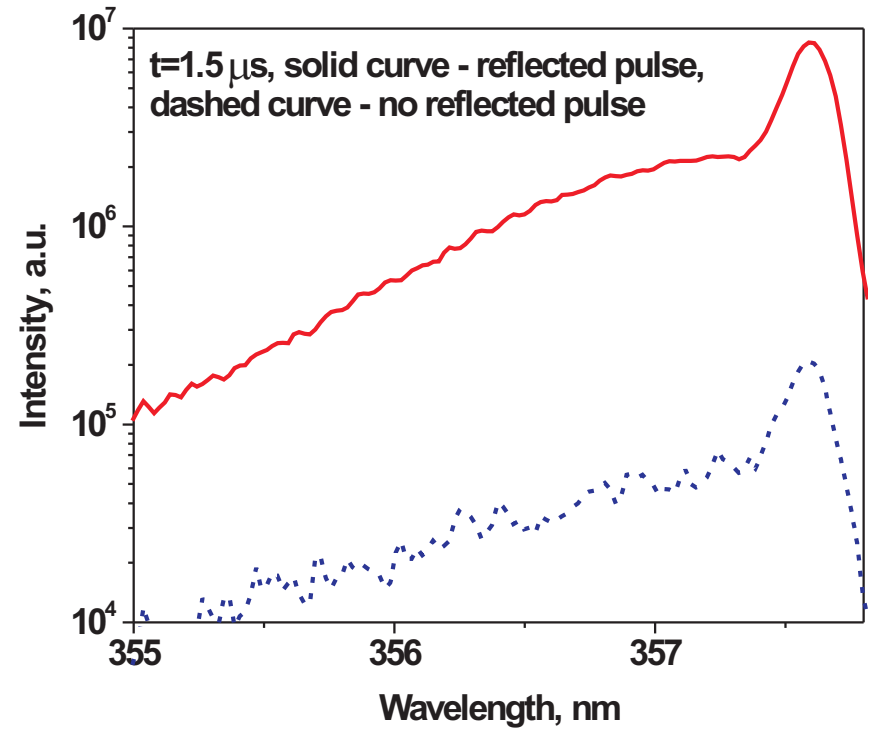

Figure 5. $\mathrm{N}_{2}: \mathrm{O}_{2}=80: 20, P=6$ mbar. An example of emission initiated by an additional pulse (solid curve) and emission present in the afterglow at time instant $1.5 \mu$ s due to pooling processes.

The distribution of deposited energy between different pulses is given by figure 6 . It is clearly seen that the energy input in the third pair of pulses is less than $10 \%$ of the energy of the incident pulse. For 3 mbar, the bulk of the energy is deposited in the second pair of pulses. For 6 and 9 mbar, roughly equal energy input is observed for the first and second pair of pulses.

This observed dependence is explained by the character of the breakdown and illustrated by the behavior of the reduced electric field, $E / N$ (see figure 7 ).

For 3 mbar, we observe essentially zero energy input in the first pair of pulses (at $t=0$ ). A sharp and short peak of the electric field (a few kTd during a few nanoseconds) is responsible for some initial ionization. The breakdown develops in the second pair of pulses, at $t \approx 245 \mathrm{~ns}$, as it is illustrated by figure 7 a. 
At 6 and 9 mbar, the peak of high electric field is followed by a pulse of a few tens of nanoseconds where the field value does not exceed 400 - 500 Td and then, 245 ns later, by a second pulse with an amplitude of $200-300 \mathrm{Td}$. The first sharp peak corresponds to a fast ionization wave, which crosses the discharge gap between the electrodes, and the pulses with duration of $20-30$ ns correspond to a stage when the discharge gap is closed to the low voltage electrode. It is during this stage when the electric current reaches its maximum value. The second pulse of the electric field, $245 \mathrm{~ns}$ later, does not contain a high peak of the electric field because the ionization is still enough for the fast ionization wave to start.

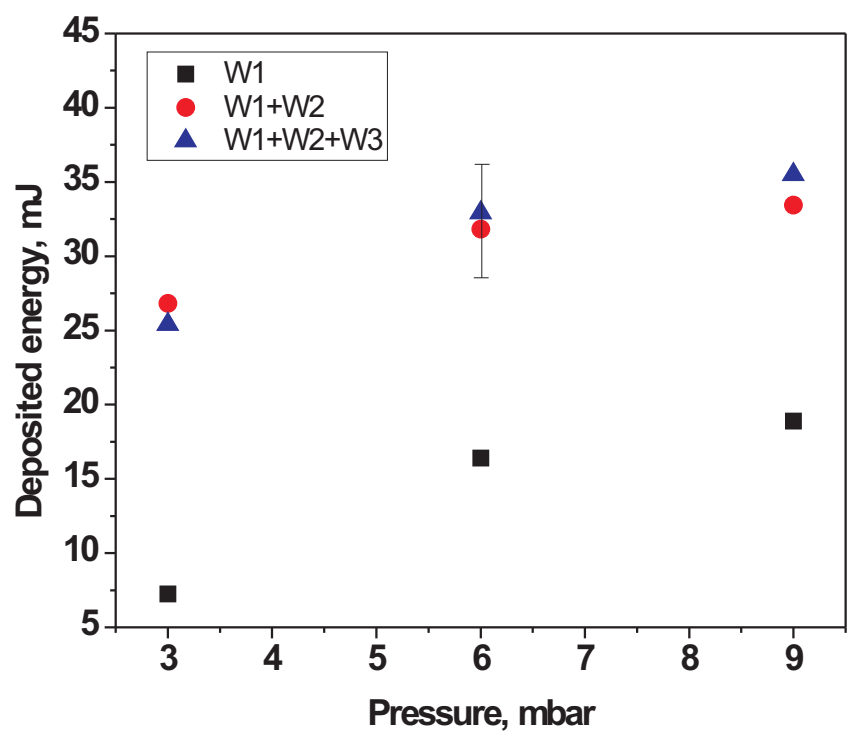

Figure 6. Deposited energy vs pressure. W1, first pair of pulses; W1+W2, first and second pairs of pulses; W1+W2+W3, total deposited energy. Total energy stored in the incident pulse from the generator is $55 \mathrm{~mJ}$.

The electric current behaves in a similar way. Figure 8 represents current measured by the first current shunt installed in a cable $12.5 \mathrm{~m}$ before the tube as a difference between the incident and the reflected pulses. It should be noted that this coincides with the transmitted current measured by a current shunt $12.5 \mathrm{~m}$ after the discharge tube with the exception of the very first step on the current pulse (first $10 \mathrm{~ns}$, see figures $8 \mathrm{~b}, \mathrm{c}$ ), which corresponds to charging the quartz tube in the process of the FIW development. Data for electric current, given by the figure 8, was taken as initial data for the calculations of kinetics in the discharge and gas heat release.

When calculating specific deposited energy from the signals of the current shunts (for details see the section 4), we assumed that the discharge was uniform between the electrodes and that no energy was deposited into the side tubes.

The results of calculations were compared to results of temperature measurements 

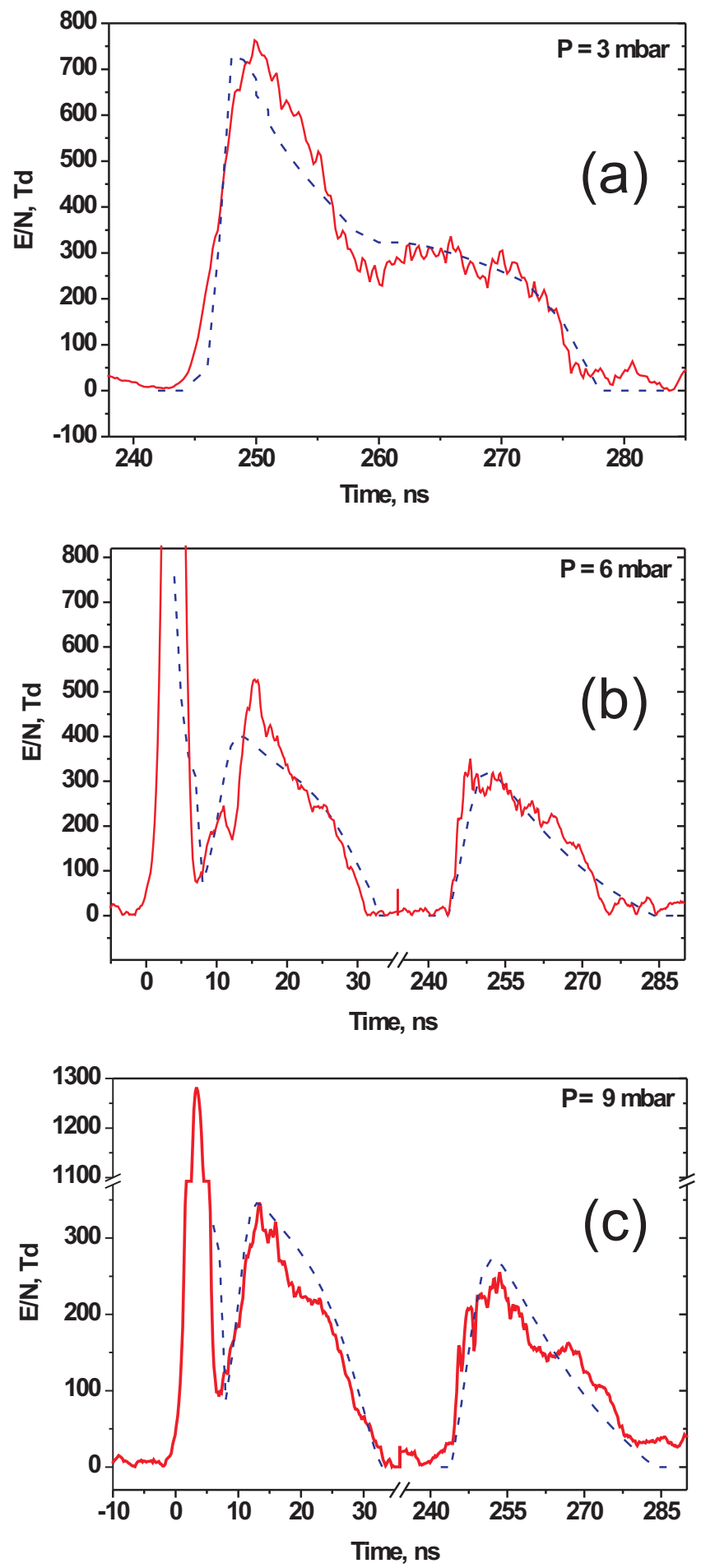

Figure 7. Reduced electric field $v s$ time. (a) $P=3 \mathrm{mbar}$, (b) $P=6 \mathrm{mbar}$ and (c) $P=9$ mbar, the data are taken $7 \mathrm{~cm}$ apart from the high-voltage electrode. Solid curves are the experimental data, dashed curves are the results of calculations. 

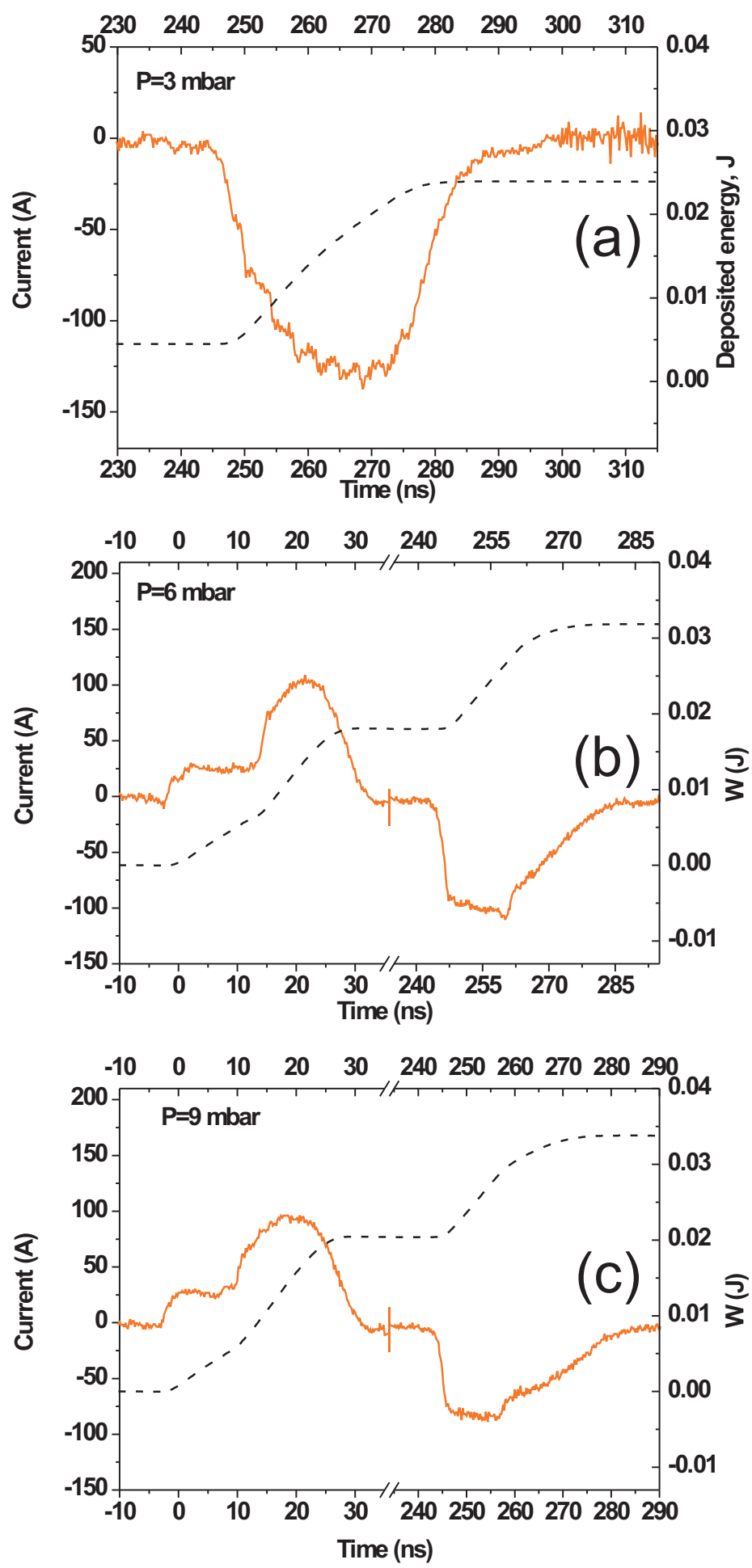

Figure 8. Electrical current (solid curves) and deposited energy (dashed curves) vs time, experimental data. (a) $P=3$ mbar, (b) $P=6$ mbar and (c) $P=9$ mbar. 
using the emission of the second positive system of molecular nitrogen.

\section{Numerical modeling and discussion}

The general description of kinetic mechanism is given by [15], and a brief explanation of modeling under given experimental conditions is presented in this section. The calculations are based on the experimentally obtained dependence of current versus time. It is assumed that the discharge gap closes fast in comparison to the total duration of the current pulse. Then, in assumption of the uniformity of the discharge parameters over the cross-section of the tube $[17,24]$, the electric field is calculated as

$$
E=\frac{I}{e \mu_{e} N_{e} S},
$$

where $I$ is the discharge current value for a given time moment, $\mu_{e}$ is the electron mobility (it is a function of reduced electric field $E / N, N$ is a gas density), $N_{e}$ is the electron density, and $S$ is the cross-section of the discharge tube.

The following equation is solved for the electron density:

$$
\frac{d N_{e}}{d t}=N_{e}\left(\nu_{i o n}-\nu_{a t t}\right)+Q_{a s s}-Q_{r e c}+Q_{d e t} .
$$

Here $\nu_{i o n}$ and $\nu_{\text {att }}$ are frequencies of ionization by electron impact and electron attachment respectively (both are functions of $E / N), Q_{r e c}$ is the rate of electron-ion recombination, $Q_{\text {det }}$ is the electron detachment rate which includes all the processes of electron detachment from the negative ions, namely the processes with participation of atoms $\mathrm{O}\left({ }^{3} \mathrm{P}\right)$, molecules $\mathrm{O}_{2}\left(\mathrm{a}^{1} \Delta_{g}\right)$ etc. [25]; and $Q_{\text {ass }}$ takes into account additional production of charged species due to associative ionization.

Similar balance equations have been written for all charged species; ten positive and negative ions have been taken into account: $\mathrm{O}_{2}^{+}, \mathrm{O}_{4}^{+}, \mathrm{O}_{2}^{+} \cdot \mathrm{N}_{2}, \mathrm{~N}_{2}^{+}, \mathrm{N}_{4}^{+}, \mathrm{NO}^{+}, \mathrm{O}^{-}$, $\mathrm{O}_{2}^{-}, \mathrm{O}_{3}^{-}, \mathrm{O}_{4}^{-}$. The system of ion-molecular reactions suggested in $[25,26]$ has been taken as a basis for calculations of the kinetics of the charged species. Ionization, dissociation and excitation rates were calculated for each time instant as a function of reduced electric field on the basis of the solution of the Boltzmann equation in a two-term approximation using BOLSIG+ code [27]. For the considered experimental conditions, the reduced electric fields in the region of significant energy input satisfies the condition $E / N \leq 1000 \mathrm{Td}$, which is why it is possible to use two-term approximation of the Boltzmann equation to determine the electron energy distribution function (EEDF) $[28,15]$. It was assumed that for given conditions the electronic excitation of species takes place by a direct electron impact from the ground state of molecules. The change of rates of the reactions with vibrational excitations of molecules was taken into account similar to [29]. The following neutral species were considered by the model: $\mathrm{N}_{2}\left(\mathrm{X}^{1} \Sigma_{g}^{+}\right), \mathrm{N}_{2}\left(\mathrm{~A}^{3} \Sigma_{u}^{+}\right), \mathrm{N}_{2}\left(\mathrm{~B}^{3} \Pi_{g}\right), \mathrm{N}_{2}\left(\mathrm{C}^{3} \Pi_{u}\right), \mathrm{N}_{2}\left(\mathrm{a}^{1} \Sigma_{u}^{-}\right), \mathrm{N}\left({ }^{4} \mathrm{~S}\right), \mathrm{N}\left({ }^{2} \mathrm{D}\right), \mathrm{N}\left({ }^{2} \mathrm{P}\right)$, $\mathrm{O}_{2}\left(\mathrm{X}^{3} \Sigma_{g}^{-}\right), \mathrm{O}_{2}\left(\mathrm{a}^{1} \Delta_{g}\right), \mathrm{O}\left({ }^{3} \mathrm{P}\right), \mathrm{O}\left({ }^{1} \mathrm{D}\right), \mathrm{O}\left({ }^{1} \mathrm{~S}\right)$. The reactions and rate constants used are given in $[1,25,30]$. To describe the gas heating in the discharge, the following processes responsible for temperature increase have been taken into account: 


\subsection{Electron recombination with molecular ions}

Energy deposited in reactions of dissociative electron-ion recombination is distributed between electronic and vibrational states of particles. At the relatively low pressures of the present experiments $(P=3-9$ mbar $)$, the main positive ions are $\mathrm{O}_{2}^{+}, \mathrm{N}_{2}^{+}, \mathrm{N}_{4}^{+}$.

The ratio of the channels of electron-ion recombination of $\mathrm{O}_{2}^{+}$and $\mathrm{N}_{2}^{+}$:

$$
\begin{array}{ll}
e+\mathrm{O}_{2}^{+} \rightarrow \text { Prod }, & k=1.95 \cdot 10^{-7} \cdot\left(300 / T_{e}\right)^{0.7} \mathrm{~cm}^{3} / \mathrm{s} \\
e+\mathrm{N}_{2}^{+} \rightarrow \text { Prod }, & k=1.8 \cdot 10^{-7} \cdot\left(300 / T_{e}\right)^{0.39} \mathrm{~cm}^{3} / \mathrm{s}
\end{array}
$$

is the following [31]:

$$
\begin{array}{rlr}
e+\mathrm{O}_{2}^{+} \rightarrow \mathrm{O}\left({ }^{3} \mathrm{P}\right)+\mathrm{O}\left({ }^{3} \mathrm{P}\right)+6.95 \mathrm{eV} & 32 \% \\
& \rightarrow \mathrm{O}\left({ }^{1} \mathrm{D}\right)+\mathrm{O}\left({ }^{3} \mathrm{P}\right)+4.99 \mathrm{eV} & 43 \% \\
& \rightarrow \mathrm{O}\left({ }^{1} \mathrm{D}\right)+\mathrm{O}\left({ }^{1} \mathrm{D}\right)+3.02 \mathrm{eV} & 20 \% \\
& \rightarrow \mathrm{O}\left({ }^{1} \mathrm{D}\right)+\mathrm{O}\left({ }^{1} \mathrm{~S}\right)+0.80 \mathrm{eV} & 5 \% \\
& \\
e+\mathrm{N}_{2}^{+} \rightarrow \mathrm{N}\left({ }^{4} \mathrm{~S}\right)+\mathrm{N}\left({ }^{4} \mathrm{~S}\right)+5.82 \mathrm{eV} & 0 \% \\
& \rightarrow \mathrm{N}\left({ }^{4} \mathrm{~S}\right)+\mathrm{N}\left({ }^{2} \mathrm{D}\right)+3.44 \mathrm{eV} & 46 \% \\
& \rightarrow \mathrm{N}\left({ }^{2} \mathrm{D}\right)+\mathrm{N}\left({ }^{2} \mathrm{D}\right)+1.06 \mathrm{eV} & 46 \% \\
& \rightarrow \mathrm{N}\left({ }^{4} \mathrm{~S}\right)+\mathrm{N}\left({ }^{2} \mathrm{P}\right)+2.25 \mathrm{eV} & 8 \%
\end{array}
$$

Thus, the energy which goes to gas heating due to reactions (3) and (4) comprises $5.0 \mathrm{eV}$ and $2.25 \mathrm{eV}$, respectively.

It was assumed that the recombination of $\mathrm{N}_{4}^{+}$ion leads to production of excited $\mathrm{N}_{2}\left(\mathrm{C}^{3} \Pi_{u}\right)$ molecules [32], and the rest of energy goes to vibrational excitation of molecular nitrogen $\mathrm{N}_{2}\left(\mathrm{X}^{1} \Sigma_{g}^{+}, v^{\prime}\right)$ :

$$
\mathrm{N}_{4}^{+}+e \rightarrow \mathrm{N}_{2}\left(\mathrm{C}^{3} \Pi_{u}, v\right)+\mathrm{N}_{2}\left(v^{\prime}\right) .
$$

In the $\mathrm{N}_{2}: \mathrm{O}_{2}$ mixture used in experiments, the density of $\mathrm{H}_{2} \mathrm{O}$ molecules did not exceed $3 \mathrm{ppm}$. It was therefore assumed that the influence of $\mathrm{H}_{2} \mathrm{O}$ molecules on ion composition and gas heating is negligible.

\subsection{Oxygen and nitrogen dissociation by electron impact}

$$
\begin{array}{ll}
e+\mathrm{N}_{2} \rightarrow e+\mathrm{N}_{2}^{*}, & \mathrm{~N}_{2}^{*} \rightarrow \mathrm{N}\left({ }^{4} \mathrm{~S}\right)+\mathrm{N}\left({ }^{2} \mathrm{D}\right)+\varepsilon_{R}, \\
e+\mathrm{O}_{2} \rightarrow e+\mathrm{O}_{2}\left(\mathrm{~B}^{3} \Sigma_{u}^{-}, v\right), & \mathrm{O}_{2}\left(\mathrm{~B}^{3} \Sigma_{u}^{-}, v\right) \rightarrow \mathrm{O}\left({ }^{3} \mathrm{P}\right)+\mathrm{O}\left({ }^{1} \mathrm{D}\right)+\varepsilon_{R}, \\
e+\mathrm{O}_{2} \rightarrow e+\mathrm{O}_{2}(\mathrm{~A}, v), & \mathrm{O}_{2}(\mathrm{~A}, v) \rightarrow \mathrm{O}\left({ }^{3} \mathrm{P}\right)+\mathrm{O}\left({ }^{3} \mathrm{P}\right)+\varepsilon_{R}
\end{array}
$$




$$
\mathrm{O}_{2}(\mathrm{~A})=\mathrm{O}_{2}\left(\mathrm{~A}^{3} \Sigma_{u}^{+}, \mathrm{C}^{3} \Delta_{u}, \mathrm{c}^{1} \Sigma_{u}^{-}\right)
$$

The dissociation of $\mathrm{N}_{2}$ and $\mathrm{O}_{2}$ molecules goes through excitation of these molecules by an electron impact and following predissociation from via electronically excited states $[33,34]$. The products of predissociation can have significant kinetic energy. This energy was calculated in the following way:

$$
\varepsilon_{R}=\varepsilon_{t h}-\varepsilon_{\text {diss }},
$$

where $\varepsilon_{t h}$ is the threshold energy for excitation of a predissociated state by an electron impact, and $\varepsilon_{\text {diss }}$ is the dissociative limit. For $\mathrm{O}_{2}\left(\mathrm{~A}^{3} \Sigma_{u}^{+}, \mathrm{C}^{3} \Delta_{u}, \mathrm{c}^{1} \Sigma_{u}^{-}\right)$states it was taken that $\varepsilon_{R}=0.8 \mathrm{eV}$, and for $\mathrm{O}_{2}\left(\mathrm{~B}^{3} \Sigma_{u}^{-}, v\right)$ it was taken that $\varepsilon_{R}=1.26 \mathrm{eV}[15]$.

\subsection{Quenching of electronically excited species of nitrogen by oxygen.}

Excited electronic states of molecular oxygen, such as $\mathrm{O}_{2}\left(\mathrm{~B}^{3} \Sigma_{u}^{-}, v\right), \mathrm{O}_{2}\left(\mathrm{~A}^{3} \Sigma_{u}^{+}, v\right)$, $\mathrm{O}_{2}\left(\mathrm{c}^{1} \Sigma_{u}^{-}, v\right)$, can be populated due to quenching of molecular nitrogen by $\mathrm{O}_{2}$ molecules. Predissociation of these levels leads to $\mathrm{O}_{2}$ dissociation and energy release to kinetic energy of created oxygen atoms. Thermalization of "hot" atoms takes place during a few collisions, and the rest of energy goes to rotational excitation of molecules and directly to gas heating. In turn, rotational-translational relaxation takes place for a few tens of collisions $[33,34]$ and so, kinetic energy of oxygen atoms transforms to gas heating.

Table 1: Quenching of electronically excited nitrogen molecules in $\mathrm{N}_{2}: \mathrm{O}_{2}$ mixtures. Main reactions.

\begin{tabular}{|l|l|l|l|}
\hline $\mathrm{N}$ & Reaction & $\mathrm{k}, \mathrm{cm}^{3} / \mathrm{s}$ & Reference \\
\hline R1. & $\mathrm{N}_{2}\left(\mathrm{~A}^{3} \Sigma_{u}^{+}\right)+\mathrm{O}_{2} \rightarrow \mathrm{N}_{2}(v)+2 \cdot \mathrm{O}\left({ }^{3} \mathrm{P}\right)+\varepsilon_{1}$ & $1.7 \cdot 10^{-12}$ & {$[1,30]$} \\
\hline R2. & $\mathrm{N}_{2}\left(\mathrm{~A}^{3} \Sigma_{u}^{+}\right)+\mathrm{O}_{2} \rightarrow \mathrm{N}_{2}(v)+\mathrm{O}_{2}\left(\mathrm{~b}^{1} \Sigma_{g}^{+}\right)$ & $7.5 \cdot 10^{-13}$ & {$[1,30]$} \\
\hline R3. & $\mathrm{N}_{2}\left(\mathrm{~A}^{3} \Sigma_{u}^{+}\right)+\mathrm{N}_{2}\left(\mathrm{~A}^{3} \Sigma_{u}^{+}\right) \rightarrow \mathrm{N}_{2}(v)+\mathrm{N}_{2}\left(\mathrm{~B}^{3} \Pi_{g}\right)$ & $7.7 \cdot 10^{-11}$ & {$[1,30]$} \\
\hline R4. & $\mathrm{N}_{2}\left(\mathrm{~A}^{3} \Sigma_{u}^{+}\right)+\mathrm{N}_{2}\left(\mathrm{~A}^{3} \Sigma_{u}^{+}\right) \rightarrow \mathrm{N}_{2}(v)+\mathrm{N}_{2}\left(\mathrm{C}^{3} \Pi_{u}\right)$ & $1.6 \cdot 10^{-10}$ & {$[1,30]$} \\
\hline R5. & $\mathrm{N}_{2}\left(\mathrm{~A}^{3} \Sigma_{u}^{+}\right)+\mathrm{O}\left({ }^{3} \mathrm{P}\right) \rightarrow \mathrm{N}_{2}(v)+\mathrm{O}\left({ }^{1} \mathrm{~S}\right)$ & $3.0 \cdot 10^{-11}$ & {$[1,30]$} \\
\hline R6. & $\mathrm{N}_{2}\left(\mathrm{~B}^{3} \Pi_{g}\right)+\mathrm{O}_{2} \rightarrow \mathrm{N}_{2}(v)+2 \cdot \mathrm{O}\left({ }^{3} \mathrm{P}\right)+\varepsilon_{6}$ & $3.0 \cdot 10^{-10}$ & {$[1,25]$} \\
\hline R7. & $\mathrm{N}_{2}\left(\mathrm{~B}^{3} \Pi_{g}, v=0\right)+\mathrm{N}_{2} \rightarrow \mathrm{N}_{2}\left(\mathrm{~A}^{3} \Sigma_{u}^{+}, v\right)+\mathrm{N}_{2}(v)$ & $2.0 \cdot 10^{-13}$ & {$[1,25]$} \\
\hline R8. & $\mathrm{N}_{2}\left(\mathrm{a}^{\prime} \Sigma_{u}^{-}\right)+\mathrm{O}_{2} \rightarrow \mathrm{N}_{2}(v)+\mathrm{O}\left({ }^{3} P\right)+\mathrm{O}\left({ }^{1} D\right)+\varepsilon_{8}$ & $2.8 \cdot 10^{-11}$ & {$[1,36]$} \\
\hline R9. & $\mathrm{N}_{2}\left(\mathrm{a}^{\prime} \Sigma_{u}^{-}\right)+\mathrm{N}_{2} \rightarrow \mathrm{N}_{2}\left(\mathrm{~B}^{3} \Pi_{g}\right)+\mathrm{N}_{2}(v)$ & $2.0 \cdot 10^{-13}$ & {$[1,36]$} \\
\hline R10. & $\mathrm{N}_{2}\left(\mathrm{C}^{3} \Pi_{u}\right)+\mathrm{O}_{2} \rightarrow \mathrm{N}_{2}(v)+2 \cdot \mathrm{O}+\varepsilon_{10}$ & $2.5 \cdot 10^{-10}$ & {$[37]$} \\
\hline R11. & $\mathrm{N}_{2}\left(\mathrm{C}^{3} \Pi_{u}\right)+\mathrm{N}_{2} \rightarrow \mathrm{N}_{2}(v)+\mathrm{N}_{2}\left(\mathrm{~B}^{3} \Pi_{g}, v\right)$ & $1.0 \cdot 10^{-11}$ & {$[37]$} \\
\hline R12. & $\mathrm{N}_{2}\left(\mathrm{C}^{3} \Pi_{u}\right) \rightarrow \mathrm{N}_{2}\left(\mathrm{~B}^{3} \Pi_{g}\right)+h \nu$ & $2.4 \cdot 10^{7} \mathrm{~s}^{-1}$ & {$[37]$} \\
\hline
\end{tabular}

The main reactions of quenching of electronically excited levels of molecular nitrogen are given in Table 1 . It should be noted that the ratio of channels of dissociation and excitation of products has been investigated for the $\mathrm{N}_{2}\left(\mathrm{~A}^{3} \Sigma_{u}^{+}\right)$state (reactions R1R2) only [30]. It is known that with an increase in the number of vibrational level of 
$\mathrm{N}_{2}\left(\mathrm{~A}^{3} \Sigma_{u}^{+}, v=0\right)$ both reaction rate [30] and ratio of channels [35] can be changed, namely the role of $\mathrm{O}_{2}$ dissociation increases. More than that, the energy release to gas heating in the reaction $\mathrm{R} 1$ depends upon the number of the vibrational level.

Reactions where energy release was taken into account, are accompanied by $\varepsilon_{R}$ in the right side of the equations in the table 1 . To calculate the energy release to translational degrees of freedom, $\varepsilon_{R}$, in the reactions $\mathrm{R} 1, \mathrm{R} 6, \mathrm{R} 8$, and $\mathrm{R} 10$ the model developed in $[1,15]$ was used. Namely, it was assumed that the probability of population of a vibrational level $v$ of a ground state of nitrogen in the reaction

$$
\begin{gathered}
\mathrm{N}_{2}^{*}+\mathrm{O}_{2} \rightarrow \mathrm{N}_{2}\left(\mathrm{X}^{1} \Sigma_{g}^{+}, v\right)+\mathrm{O}\left({ }^{3} \mathrm{P}\right)+\mathrm{O}\left({ }^{3} \mathrm{P},{ }^{1} \mathrm{D}\right), \\
\mathrm{N}_{2}^{*}=\mathrm{N}_{2}\left(\mathrm{~A}^{3} \Sigma_{u}^{+}, v^{\prime}\right), \mathrm{N}_{2}\left(\mathrm{~B}^{3} \Pi_{g}\right), \mathrm{N}_{2}\left(\mathrm{a}^{\prime 1} \Sigma_{u}^{-}\right), \mathrm{N}_{2}\left(\mathrm{C}^{3} \Pi_{u}\right)
\end{gathered}
$$

is proportional to a Frank-Condon factor $q_{v}$ of a transition between initial and final state of a nitrogen molecule: $\mathrm{N}_{2}^{*} \rightarrow \mathrm{N}_{2}\left(\mathrm{X}^{1} \Sigma_{g}^{+}, v\right)$. The energy release $\varepsilon_{R}$ was calculated as $[1,15]$

$$
\varepsilon_{R}=\varepsilon^{*}-\varepsilon_{d i s s}-\sum_{v} q_{v} \varepsilon_{v}
$$

where $\varepsilon^{*}$ is the energy of excited state of molecular nitrogen $\mathrm{N}_{2}^{*}, \varepsilon_{\text {diss }}$ is the dissociative limit of created electronic state of molecular oxygen, and $\varepsilon_{v}$ is the energy of the vibrational excitation of the $\mathrm{N}_{2}\left(\mathrm{X}^{1} \Sigma_{g}^{+}, v\right)$ molecules. A summation is made only for the vibrational levels for which the following property holds: $\sum q_{v} \varepsilon_{v} \leq \varepsilon^{*}-\varepsilon_{\text {diss }}$.

It should be noted that there is a significant uncertainty in energy release to gas heating, $\varepsilon_{R}$, in the process of $\mathrm{N}_{2}\left(\mathrm{C}^{3} \Pi_{u}\right)$ quenching (reaction $\mathrm{R} 10$ ). The products of this reaction, in particular the electronic states of produced oxygen atoms, are not known $[13,15]$. At the same time excitation of this electronic state is very efficient at high electric fields and its quenching must be important for mechanism of fast gas heating $[13,15]$. At our experimental conditions of relatively low gas pressure, the main channel of $\mathrm{N}_{2}\left(\mathrm{C}^{3} \Pi_{u}\right)$ desactivation is radiative quenching (R12) rather than quenching by oxygen (R10), so it is possible to avoid the mentioned uncertainty.

\subsection{Quenching of $\mathrm{O}\left({ }^{1} D\right)$ atoms}

Reactions of dissociation of molecular oxygen often lead to production of excited $\mathrm{O}\left({ }^{1} \mathrm{D}\right)$ atoms. In nitrogen-oxygen mixtures these atoms can be quenched in the following reactions [25]:

$$
\begin{aligned}
& \mathrm{O}\left({ }^{1} \mathrm{D}\right)+\mathrm{N}_{2} \rightarrow \mathrm{O}\left({ }^{3} \mathrm{P}\right)+\mathrm{N}_{2}(v)+\varepsilon_{R}, k=1.8 \cdot 10^{-11} \cdot \exp (107 / T) \mathrm{cm}^{3} / \mathrm{s} \\
& \mathrm{O}\left({ }^{1} \mathrm{D}\right)+\mathrm{O}_{2} \rightarrow \mathrm{O}\left({ }^{3} \mathrm{P}\right)+\mathrm{O}_{2}\left(b^{1} \Sigma_{g}^{+}, v\right), k=2.56 \cdot 10^{-11} \cdot \exp (67 / T) \mathrm{cm}^{3} / \mathrm{s} \\
& \mathrm{O}\left({ }^{1} \mathrm{D}\right)+\mathrm{O}_{2} \rightarrow \mathrm{O}\left({ }^{3} \mathrm{P}\right)+\mathrm{O}_{2}\left(X^{3} \Sigma_{g}^{-}, v\right), \quad k=0.64 \cdot 10^{-11} \cdot \exp (67 / T) \mathrm{cm}^{3} / \mathrm{s}
\end{aligned}
$$

Quenching of $\mathrm{O}\left({ }^{1} \mathrm{D}\right)$ by molecular nitrogen has been studied in a number of papers. It was demonstrated that this reaction goes through the intermediate complex, at this 
$30 \pm 10 \%$ of energy goes to vibrational excitation of $\mathrm{N}_{2}$ [1]. Based on this, it was assumed that $\cong 70 \%$ of $\mathrm{O}\left({ }^{1} \mathrm{D}\right)$ excitation energy is spent for gas heating, that is that for the reaction $(9) \varepsilon_{R} \cong 1.38 \mathrm{eV}$.

\subsection{Reactions of VT-relaxation of vibrationally excited $\mathrm{N}_{2}(v)$ molecules}

An important processes of vibrational desactivation of $\mathrm{N}_{2}(v)$ molecules in $\mathrm{N}_{2}: \mathrm{O}_{2}$ mixtures is vibrational-translational (VT) relaxation on $\mathrm{O}\left({ }^{3} \mathrm{P}\right)$ atoms:

$$
\mathrm{N}_{2}(v)+\mathrm{O}\left({ }^{3} \mathrm{P}\right) \rightarrow \mathrm{N}_{2}(v-1)+\mathrm{O}\left({ }^{3} \mathrm{P}\right)+\varepsilon_{R} .
$$

These reactions at the conditions of a relatively high dissociation degree of $\mathrm{O}_{2}$ are significant for gas heating. To describe $\mathrm{VT}$ - relaxation of $\mathrm{N}_{2}(v)$ on $\mathrm{O}\left({ }^{3} \mathrm{P}\right)$ atoms, the reaction rate constant from [38] was taken:

$$
\mathrm{N}_{2}(v=1)+\mathrm{O}\left({ }^{3} \mathrm{P}\right) \rightarrow \mathrm{N}_{2}(v=0)+\mathrm{O}\left({ }^{3} \mathrm{P}\right), \quad k_{V T}=4.5 \cdot 10^{-15} \cdot\left(\frac{T}{300}\right)^{2.1} \mathrm{~cm}^{3} / \mathrm{s} .
$$

As far as for the given conditions VT - relaxation of $\mathrm{O}_{2}$ and NO molecules is fast, vibrational temperatures of these molecules were considered to be equal to translational temperature of the gas.

Evolution of a gas temperature was described by the following equation:

$$
C_{v} N \cdot \frac{d T}{d t}=\frac{\varepsilon-\varepsilon_{v}(T)}{\tau_{V T}}+W_{R}
$$

where $C_{v}$ is the specific heat capacity at constant volume, $N$ is the gas density, $\varepsilon_{v}$ is the average vibrational energy per $\mathrm{N}_{2}$ molecule, $\tau_{V T}$ is the characteristic time of VT relaxation of $\mathrm{N}_{2}(v)$, and $W_{R}$ is the rate of gas heating in chemical reactions.

Equation (10) describes gas heating in an isochore assumption, which is true for the condition of given experiments. Indeed, typical times for gas-dynamic processes are equal to $\tau_{g} \cong 300 \mu \mathrm{s}$ at a tube length of $L=20 \mathrm{~cm}$. As far as the process of fast gas heating is considered within a time scale of $t<50 \mu s<<\tau_{g}$, the isochore assumption is valid for the central part of the discharge tube.

Gas cooling due to the thermal conductivity is not considered by equation (10). It follows from estimates that at $P \geq 3$ mbar, $T \leq 450 \mathrm{~K}$ and discharge tube radius $R=0.45 \mathrm{~cm}$ it is possible to disregard this process for times less than $50 \mu \mathrm{s}$.

\section{Temperature measurements and results of numerical calculations}

Temporal behavior of the discharge current was taken from experiments (see figure 8). All three successive pulses discussed in the section 3 were taken into account. The reduced electric field $E / N$ was calculated as described in the section 4 . Figure 7 represents calculated reduced electric fields (dashed curves) together with results of measurements (solid curves). It is clearly seen that for all pressures under consideration 


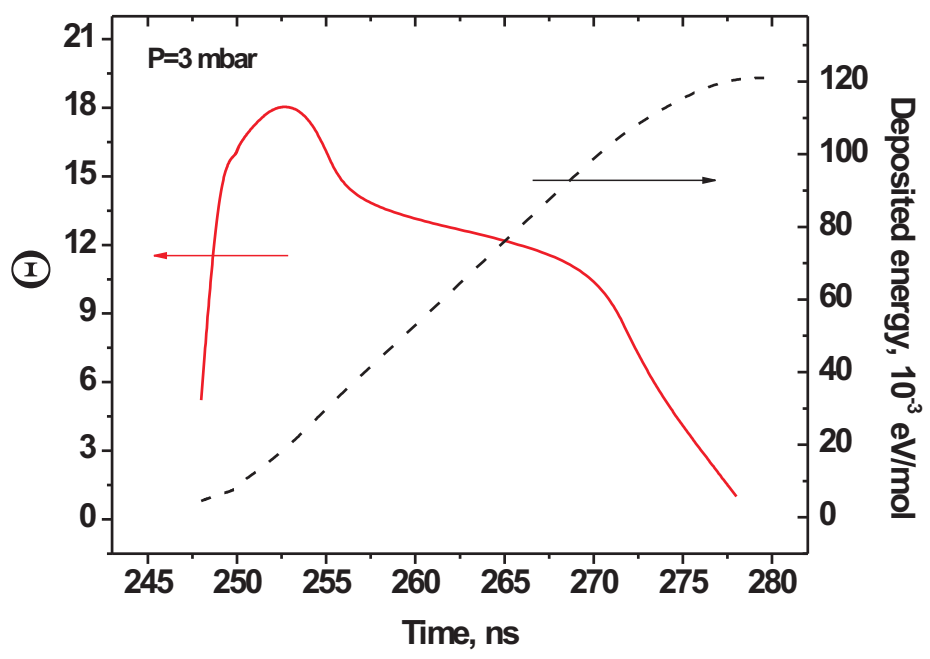

Figure 9. Factor $\Theta$, describing a number of inelastic collisions (solid curve), and specific deposited energy (dashed curve) vs time. $P=3$ mbar.

(3, 6 and 9 mbar) the coincidence between calculations and measurements is good, which provides an adequate description of ionization, dissociation and excitation by electron impact during the discharge phase. At relatively low gas pressures and fast change of $E / N$ it is important to estimate if stationary solution of the Boltzmann equation is applicable for EEDF calculations. The $\Theta$ factor, describing a number of non-elastic collisions of electrons during a typical time of $E / N$ change, has been calculated:

$$
\Theta=\nu_{u} \cdot\left(\frac{1}{E} \cdot\left|\frac{d E}{d t}\right|\right)^{-1},
$$

here $\nu_{u}$ is the effective frequency of relaxation of energy of electrons [39]. Factor $\Theta$ versus time for our experimental conditions at $P=3 \mathrm{mbar}$ is given by figure 9 . It is evident that $\Theta>>1$ for the region of a main energy input. Similar results were obtained for 6 and 9 mbar. Therefore the EEDF relaxation in the region of thresholds of non-elastic processes takes place and the use of a stationary solution of the Boltzmann equation is possible.

To summarize the energy input, table 2 gives a comparison of experimentally measured and calculated values for all three pulses. For present experimental conditions, the main energy input takes place at $E / N=200-400 \mathrm{Td}$, providing efficient electronic excitation and dissociation of molecules, with the following increase of gas temperature.

Calculated kinetic curves for charged species are presented in figure 10. The main positive ions at our experimental conditions are $\mathrm{N}_{2}^{+}$and $\mathrm{O}_{2}^{+}$. The density of $\mathrm{N}_{4}^{+}$complex ions is low because of a low overall gas density, and so it does not change the efficient coefficient of electron-ion recombination. The density of negative ions is not higher than the $\mathrm{N}_{4}^{+}$density and thus is not given in the figure. For $\mathrm{N}_{2}^{+}$ions, other important 


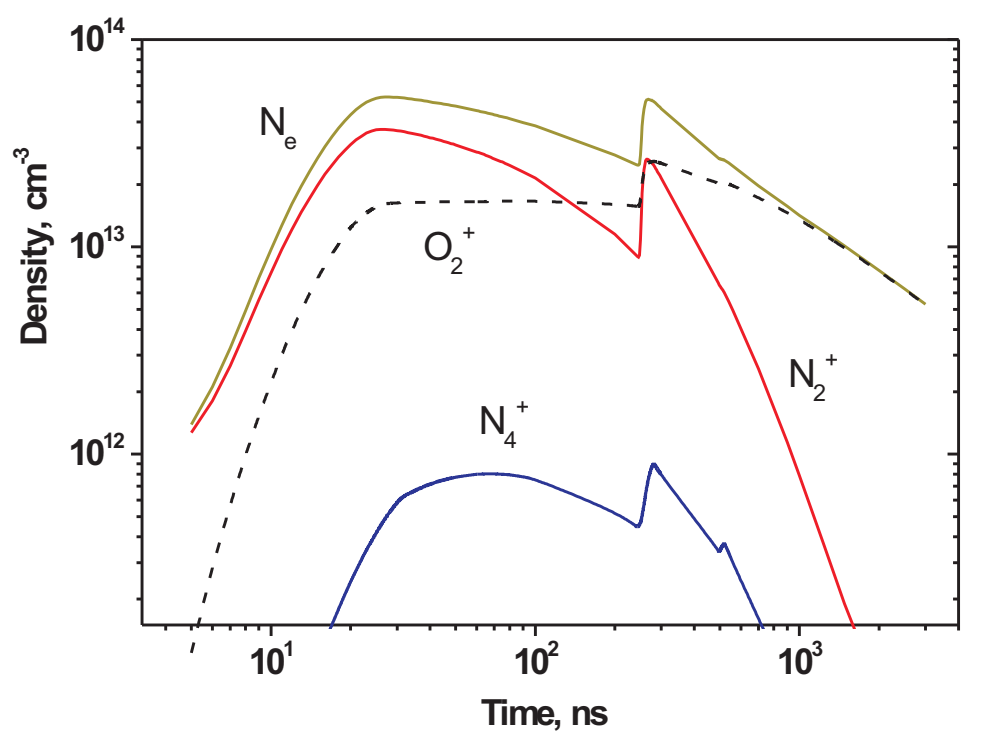

Figure 10. Kinetic curves for main charged species at gas pressure $P=6$ mbar.

processes of recombination are charge exchange on molecular oxygen $\mathrm{N}_{2}^{+}+\mathrm{O}_{2} \rightarrow \mathrm{O}_{2}^{+}+\mathrm{N}_{2}$ and conversion to $\mathrm{N}_{4}^{+}: \mathrm{N}_{2}^{+}+\mathrm{N}_{2}+\mathrm{M} \rightarrow \mathrm{N}_{4}^{+}+\mathrm{M}$.

Table 2: Specific deposited energy $\left(10^{-3} \mathrm{eV} / \mathrm{mol}\right)$ for three pulses $w_{1}, w_{2}$ and $w_{3}$ for gas pressures 3,6 and 9 mbar.

\begin{tabular}{|l|l|l|l|}
\hline & $w_{1}(\exp /$ calc $)$ & $w_{1}+w_{2}(\exp /$ calc $)$ & $w_{1}+w_{2}+w_{3}(\exp /$ calc $)$ \\
\hline 3 mbar & $3.0 / 3.5$ & $120.4 / 121.0$ & $129.6 / 129.0$ \\
\hline 6 mbar & $53.0 / 53.6$ & $102.8 / 103.0$ & $107.0 / 107.0$ \\
\hline 9 mbar & $40.7 / 40.7$ & $72.0 / 72.4$ & $76.5 / 76.6$ \\
\hline
\end{tabular}

The results of calculations of $\mathrm{O}\left({ }^{3} \mathrm{P}\right), \mathrm{N}_{2}\left(\mathrm{~A}^{3} \Sigma_{u}^{+}\right), \mathrm{N}_{2}\left(\mathrm{~B}^{3} \Pi_{g}\right)$, and $\mathrm{N}_{2}\left(\mathrm{C}^{3} \Pi_{u}\right)$ densities at $P=6 \mathrm{mbar}$ are shown in figure 11. The same figure gives (indicated with points) results of $\left.\left[\mathrm{N}_{2}\left(\mathrm{~A}^{3} \Sigma_{u}^{+}\right), v=0\right)\right]$ measurements in arbitrary units. A high degree of dissociation of molecular oxygen by the discharge $\left(\left[\mathrm{O}\left({ }^{3} \mathrm{P}\right)\right] /\left[\mathrm{O}_{2}\right] \approx 10 \%\right)$ should be noted.

For a pressure range of our experiments, the typical times of the discharge processes responsible for fast gas heating in the discharge afterglow are the following: quenching of the $\mathrm{N}_{2}\left(\mathrm{~B}^{3} \Pi_{g}\right)$ state of nitrogen by molecular oxygen (reaction R6) takes approximately $100 \mathrm{~ns}$, electron-ion recombination of $\mathrm{N}_{2}^{+}$and $\mathrm{O}_{2}^{+}$ions takes hundreds of nanoseconds, and quenching of the metastable $\mathrm{N}_{2}\left(\mathrm{~A}^{3} \Sigma_{u}^{+}\right)$level (reaction R1) needs tens of microseconds. Thus, at time equal to approximately $50 \mu \mathrm{s}$ the fast energy release stops. Further increase of gas temperature can be connected with the recombination of atomic oxygen and VT-relaxation of $\mathrm{N}_{2}(v)$ molecules. Under the considered conditions, these processes take place with typical times of more than tens of milliseconds, and were 


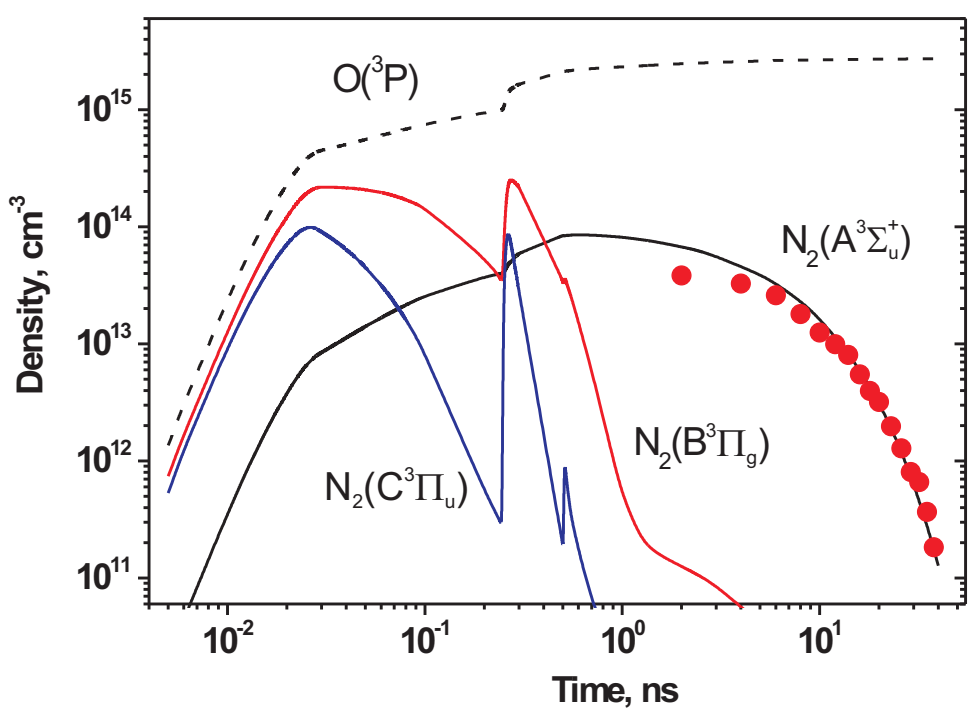

Figure 11. Kinetic curves for main excited species at gas pressure $P=6$ mbar. Experimental points for $\mathrm{N}_{2}\left(A^{3} \Sigma_{u}^{+}\right)$are given in arbitrary units.

not considered.

Figure 12 presents experimental data and results of calculations of temperature increase in the discharge and near afterglow. It should be noted that the accuracy of measurements of a deposited energy is about $10 \%$. The deviation of non-averaged electrical current from experiment to experiment can be as high as $5-7 \%$. Numerical modeling was based on single-shot pulse oscillograms. It follows from Fig. 12 that although deviations are present in the calculations for different gas pressures, they do not exceed $10 \%$ of relative error in temperature, what coincides reasonably well with measured gas temperature. It follows from the calculations that a significant fraction of the energy goes into gas heating at a sub-microsecond time scale immediately after each discharge pulse. As already mentioned, this is connected with quenching of excited nitrogen by molecular oxygen and quenching of excited $\mathrm{O}\left({ }^{1} \mathrm{D}\right)$ atoms on $\mathrm{N}_{2}$ molecules. It should be noted that with electric field, further change of the mechanisms of fast gas heating can be observed. It was suggested in [13] that all the energy released in reactions of ion-ion recombination, is spent on gas heating and leads to significant temperature increase. In particular, reactions

$$
\begin{aligned}
& \mathrm{N}_{2}^{+}+\mathrm{N}_{2}+\mathrm{M} \rightarrow \mathrm{N}_{4}^{+}+\mathrm{M}, \\
& \mathrm{N}_{4}^{+}+\mathrm{O}_{2} \rightarrow \mathrm{O}_{2}^{+}+\mathrm{N}_{2}+\mathrm{N}_{2}, \\
& \mathrm{~N}_{2}^{+}+\mathrm{O}_{2} \rightarrow \mathrm{O}_{2}^{+}+\mathrm{N}_{2},
\end{aligned}
$$

give $1.1 \mathrm{eV}, 2 \mathrm{eV}$ and $3.1 \mathrm{eV}$, respectively. Our experimental conditions do not allow check of the validity of the given assumption: the additional gas heating due to these 

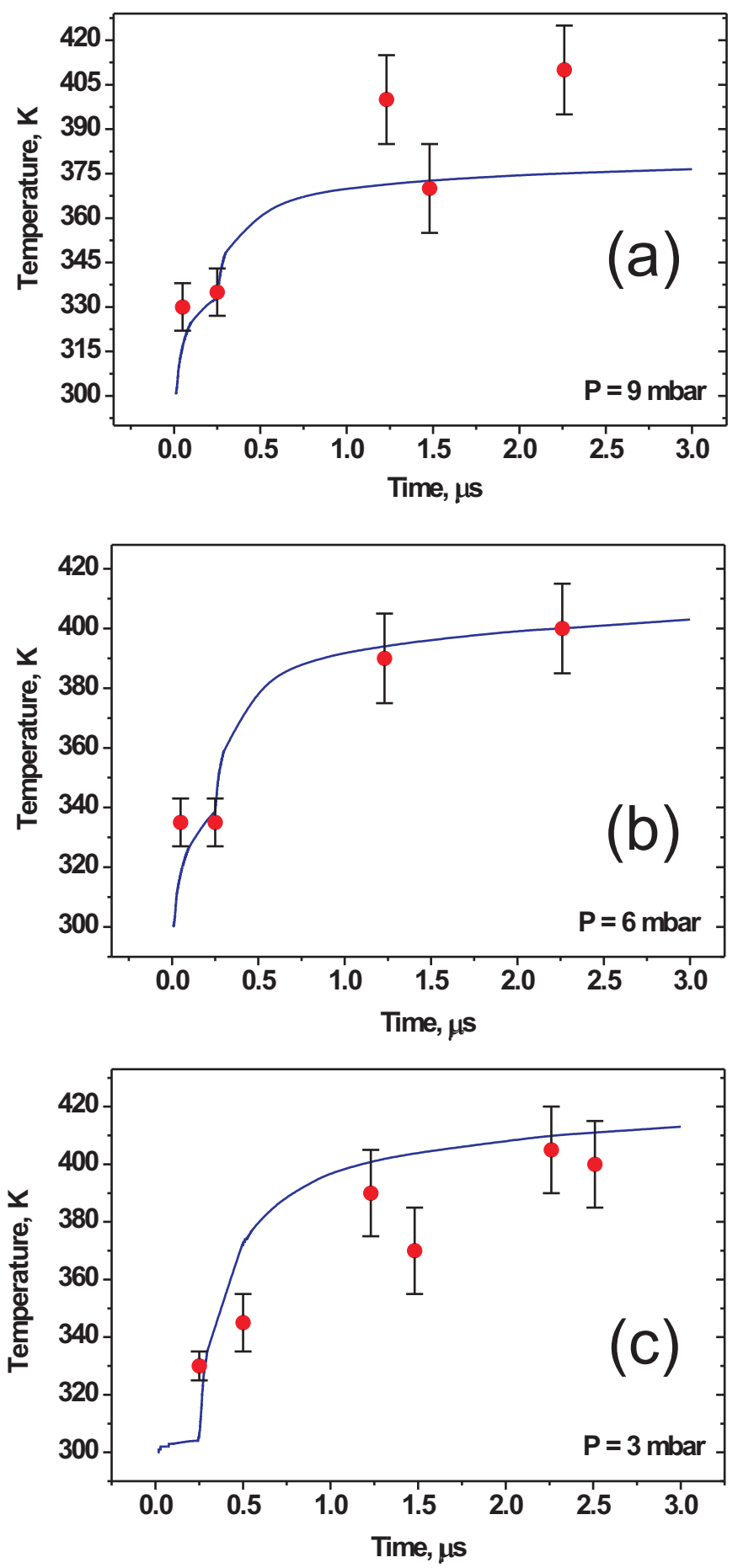

Figure 12. Gas temperature vs time. Symbols - experimental data, curves - results of calculations. 


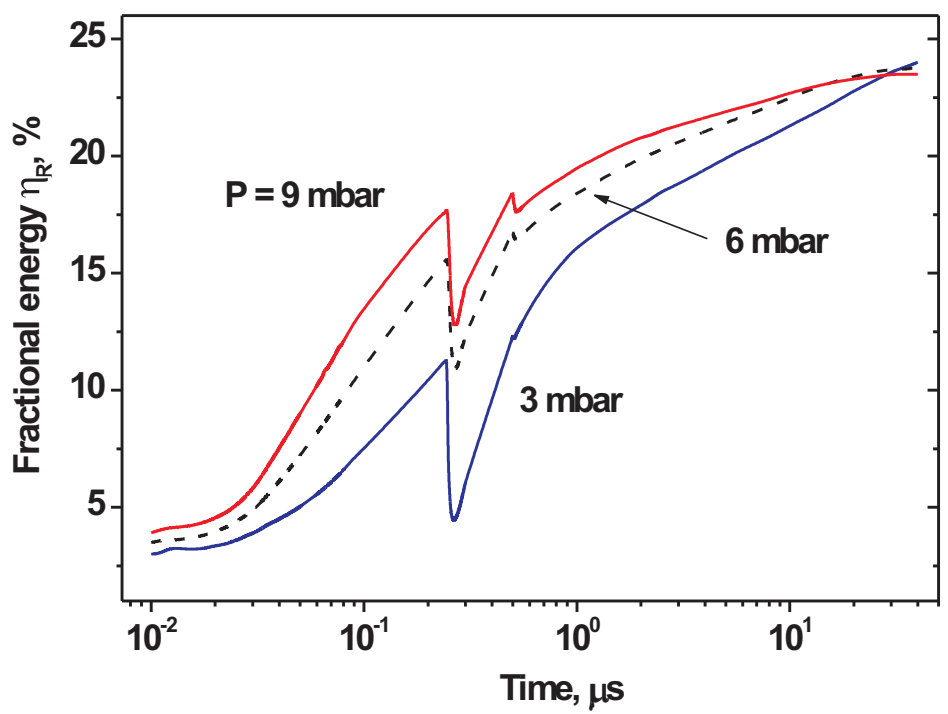

Figure 13. Fraction of discharge energy $\eta_{R} v s$ time which goes to fast gas heating for different gas pressures.

processes does not exceed $2-3 \mathrm{~K}$ because of relatively low energy release to ionization at $E / N=200-400 \mathrm{Td}$ and negligible role of complex ions at $3-9 \mathrm{mbar}$ [15]. To affirm or refute the suggestion of [13], the pulsed discharge should be organized uniformly in space, at high pressures, with extremely high electric fields $E / N>600-800 \mathrm{Td}$ in the region of main energy release, and with specific deposited energy on the level of $0.1 \mathrm{eV} /$ molecule or higher. Such a discharge system is a challenge for kinetic study.

It is seen from figure $12 \mathrm{a}-\mathrm{b}$ that at $P=6$ and 9 mbar at time $t=240$ ns the gas temperature increase is equal to $30-35 \mathrm{~K}$. At $P=3$ mbar energy input in the first pulse is small, and gas heating is absent. The main temperature increase takes place after the second pulse. Calculated temperatures at $P=9$ mbar, 6 mbar and 3 mbar $3 \mu$ s after the discharge are $375 \mathrm{~K}, 400 \mathrm{~K}$ and $410 \mathrm{~K}$, respectively. The specific deposited energy increases by 1.7 times when pressure decreases, from $w=76.5 \cdot 10^{-3} \mathrm{eV} / \mathrm{mol}$ at 9 mbar to $w=129 \cdot 10^{-3} \mathrm{eV} / \mathrm{mol}$ at $3 \mathrm{mbar}$. The main reason for different relative values of gas heating $(\Delta T / T)$ and specific energy input $(\Delta w / w)$ is the dynamics of fast gas heating. Indeed, figure 13 presents fraction of a discharge energy $\eta_{R}$ which goes to fast gas heating for different gas pressures. It is clearly seen from the Figure that fractional energy, that is the ratio of gas heating to the energy release in the discharge, drops significantly at $250 \mathrm{~ns}$. This fact is due to a sharp increase of energy release at the instant when the second (reflected) pulse comes to the discharge gap. Gas excitation by an electron impact is much faster than the relaxation due to quenching of excited species. The difference in time between the excitation and relaxation increase when the pressure drops. Moreover, the energy input in the second pulse is the highest for 3 Torr. 


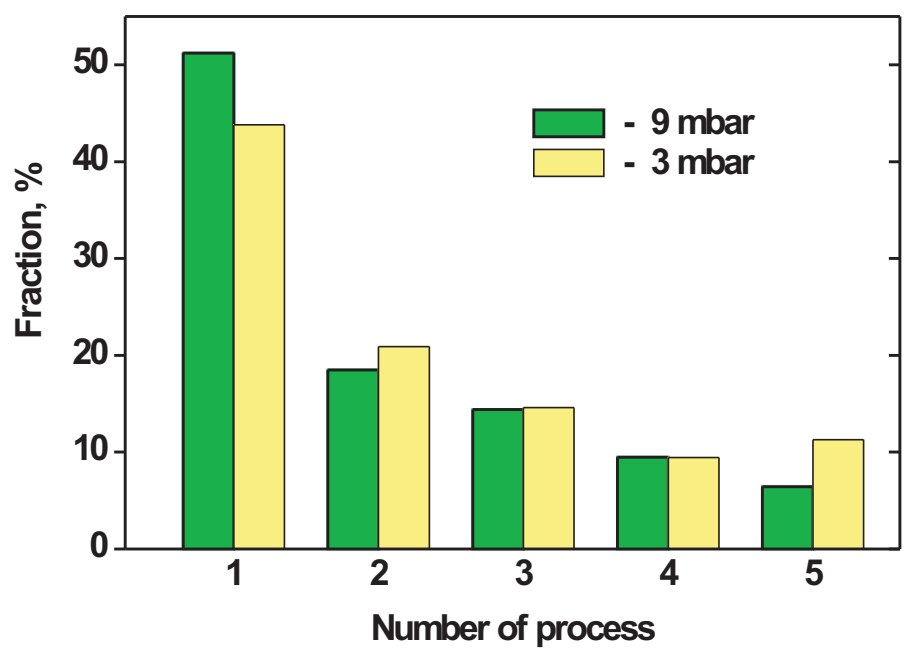

Figure 14. Distribution of energy release in fast gas heating between different processes under experimental conditions of the present paper: 1 - quenching of $\mathrm{N}_{2}\left(\mathrm{~B}^{3} \Pi_{g}\right), \quad \mathrm{N}_{2}\left(\mathrm{C}^{3} \Pi_{u}\right)$ by $\mathrm{O}_{2}(\mathrm{R} 6, \mathrm{R} 10) ; 2$ - quenching of $\mathrm{O}\left({ }^{1} \mathrm{D}\right)$ by $\mathrm{N}_{2} ; 3$ dissociation of $\mathrm{N}_{2}$ and $\mathrm{O}_{2}$ by an electron impact (10); 4 - quenching of $\mathrm{N}_{2}\left(\mathrm{~A}^{3} \Sigma_{u}^{+}\right)$, $\mathrm{N}_{2}\left(\mathrm{a}^{1} \Sigma_{u}^{-}\right)$by $\mathrm{O}_{2}(\mathrm{R} 1, \mathrm{R} 8), 5$ - reactions of dissociative electron-ion recombination of $\mathrm{N}_{2}^{+}$and $\mathrm{O}_{2}^{+}(6,7)$

As a result, the decrease of the fractional energy at $250 \mathrm{~ns}$ is the most pronounced for lower pressure. For all the considered pressures, $\eta_{R}$ reaches its quasistationary value, equal to $\eta_{R} \approx 24 \%$, at a typical time of $t>40-50 \mu \mathrm{s}$.

Figure 14 presents the relative roles of different processes in the mechanism of fast gas heating under the considered conditions of moderate pressures and reduced electric fields within a range of $200-400 \mathrm{Td}$. The main energy release takes place in reactions of the quenching of electronically excited nitrogen molecules, such as $\mathrm{N}_{2}\left(\mathrm{~B}^{3} \Pi_{g}, \mathrm{C}^{3} \Pi_{u}\right)$ by oxygen and the quenching of excited $\mathrm{O}\left({ }^{1} \mathrm{D}\right)$ atoms by $\mathrm{N}_{2}$. These processes provide about $65 \%$ of the total gas heating. The pressure range of $3-9$ mbar is a boundary range, wherein the radiative quenching of the $\mathrm{N}_{2}\left(\mathrm{C}^{3} \Pi_{u}\right)$ to the $\mathrm{N}_{2}\left(\mathrm{~B}^{3} \Pi_{g}\right)$ state with following collisional quenching is replaced by collisional quenching of $\mathrm{N}_{2}\left(\mathrm{C}^{3} \Pi_{u}\right)$. So, with pressure decrease, the input of the collisional quenching of the $\mathrm{N}_{2}\left(\mathrm{~B}^{3} \Pi_{g}\right)$ and $\mathrm{N}_{2}\left(\mathrm{C}^{3} \Pi_{u}\right)$ states to gas heating becomes less important. At the same time, heating due to electron-ion recombination increases because of $E / N$ increase.

According to calculations, under given experimental conditions at $50-100 \mu \mathrm{s}$ after the discharge the energy branching in the process of fast gas heating is the following: approximately $24 \%$ of the energy goes to gas heating, $43-47 \%$ (depending upon gas pressure) to dissociation of molecular oxygen and the rest to vibrational excitation of molecular nitrogen. This distribution is determined, first of all, by 
dynamics of the reduced electric field (see figure 7). The main energy release takes place at $E / N=200-400 \mathrm{Td}$, and this leads to efficient gas heating via relaxation of electronically excited states and dissociation of molecular oxygen. It should be noted that the energy cost of atomic oxygen production is rather high: $G=18-19$ (here $\mathrm{G}$ is a number of oxygen atoms produced for $100 \mathrm{eV}$ of deposited energy), which is close to a maximum value possible for gas discharges in air.

\section{Conclusions}

Experimental studies of parameters of a spatially uniform nanosecond discharge in air in a pressure range 3-9 mbar have been made. Temporal behavior of the discharge current, reduced electric field $E / N$ and specific deposited energy were measured. The data was used for development and verification of a numerical model of kinetics in the discharge. Due to the relatively small diameter of the discharge tube, the current density was high (160-200 A/ $\left.\mathrm{cm}^{2}\right)$. This provided high specific deposited energy $(0.1-0.13 \mathrm{eV} /$ molecule $)$ at reduced electric fields of $200-400 \mathrm{Td}$.

The evolution of gas temperature has been studied in the discharge and in the afterglow. The temperature was measured from the rotational structure of the second positive system of molecular nitrogen. The data in the afterglow was obtained with the help of additional nanosecond pulses of relatively low intensity. Thus, fast gas heating in an $\mathrm{N}_{2}: \mathrm{O}_{2}=4: 1$ mixture has been measured for the first time with well-controlled electric fields and specific energy input during the discharge stage for $E / N=200-400 \mathrm{Td}$. The results prove that the main energy input to gas heating takes place at time typical for quenching of electronically excited states of molecular nitrogen.

The results of numerical calculations based on a given experimental electric current profile versus time are presented. The calculations were carried out in the framework of a 0D kinetic model, taking into account the detailed kinetics of charged and excited species. To describe gas heating, a kinetic mechanism $[1,15]$ has been used. The calculated behavior of the electric field and specific deposited energy is in good agreement with the experiments, which proves that the model describes correctly electric field and processes of ionization.

There exists a set of processes with unknown percentage of energy release to fast gas heating. Among them are the reactions of $\mathrm{N}_{2}\left(\mathrm{C}^{3} \Pi_{u}\right)$ quenching by molecular oxygen and reactions of electron-ion and ion-ion recombination. As far as the influence of these reactions decreases with pressure, study of fast gas heating at relatively low gas pressures can be considered as a basis for verification of the models suggested.

The main energy release in the model takes place in reactions of quenching of electronically excited nitrogen molecules, such as $\mathrm{N}_{2}\left(\mathrm{~A}^{3} \Sigma_{u}^{+}, \mathrm{B}^{3} \Pi_{g}, \mathrm{C}^{3} \Pi_{u}\right.$, a $\left.{ }^{\prime 1} \Sigma_{u}^{-}\right)$by oxygen, quenching of excited $\mathrm{O}\left({ }^{1} \mathrm{D}\right)$ atoms by $\mathrm{N}_{2}$, and in reactions of nitrogen and oxygen dissociation by electron impact. These processes provide more than $80 \%$ of total gas heating. An agreement between experimental data and results of calculations of gas temperature has been obtained for pressures 3, 6 and 9 mbar. The observed temperature 
increase in the afterglow is connected with the relaxation of electronic excitation, namely relaxation of $\mathrm{O}\left({ }^{1} \mathrm{D}\right)$ and $\mathrm{N}\left({ }^{2} \mathrm{D}\right)$ atoms and $\mathrm{N}_{2}\left(\mathrm{~A}^{3} \Sigma_{u}^{+}, \mathrm{B}^{3} \Pi_{g}, \mathrm{C}^{3} \Pi_{u}, \mathrm{a}^{1} \Sigma_{u}^{-}\right)$molecules, so the suggestion concerning the mechanism of fast gas heating in [1] is confirmed experimentally. Typical times of these reactions do not exceed a few microseconds, which is why under our experimental conditions the main energy relaxation takes place during 50-100 microseconds. During this time, about $24 \%$ of the discharge energy goes to fast gas heating.

\section{Acknowledgements}

The authors are thankful to Prof. Martin Gundersen for discussions and for developing the collaborative relations between USC and LPP EP and to M. Jean Guillon for technical assistance. Two-month fellowship of S. J. Pendleton was supported by ONR and NumerEx, LLC award 09-003, and the NSF GRFP Travel Grant. Work of N. Popov was partially supported by Grant for Support of Leading Scientific Schools N 3322.2010.2. The work was partially supported by French National Agency, ANR (RAMPE Project), CNRS-RAS (collaborative grant 23994), PICS (11.02.91063-a/5745) and EOARD AFOSR, grant FA8655-10-1-3018.

[1] Popov N A 2001 Investigation of the mechanism for rapid heating of nitrogen and air in gas discharge Plasma Phys. Rep. 27(10) 886

[2] Starikovskaia S M and Starikovskii A Yu 2010 Plasma-Assisted Ignition and Combustion, in: Handbook of Combustion, Vol. 5: New Technologies, Lackner M, Winter F, Agarwal A K, eds. WILEY VCH Verlag GmbH \& Co. KGaA, p. 71

[3] Adamovich I V, Choi I, Jiang N, Kim J-H, Keshav S, Lempert W R, Mintusov E, Nishihara M, Samimy M and Uddi M 2009 Plasma assisted ignition and high-speed flow control: non-thermal and thermal effects Plasma Sources Sci. Technol. 18034018 (13pp)

[4] Starikovskii A Yu, Nikipelov A A, Nudnova M M and Roupassov D V 2009 SDBD plasma actuator with nanosecond pulse-periodic discharge Plasma Sources Sci. Technol 18 034015(17 pp)

[5] Miles R B, Opaits D F, Shneider M N, Zaidi S H and Macheret S O 2009 Non-thermal atmospheric pressure plasmas for aeronautic applications Eur. Phys. J. Appl. Phys. 4722802

[6] Aleksandrov N L, Kindysheva S V, Kosarev I N, Starikovskaia S M, Starikovskii A Yu 2009 Mechanism of ignition by non-equilibrium plasma 2009 Proc. of the Combustion Institute 32 205

[7] Adamovich I V, Choi I, Jiang N, Kim J-H, Keshav S, Lempert W R, Mintusov E, Nishihara M, Samimy M and Uddi M 2009 Repetitively pulsed nonequilibrium plasmas for magnetohydrodynamic flow control and plasma-assisted combustion Plasma Sources Sci. Technol. 18034018 (13pp)

[8] Pai D Z, Lacoste D A and Laux C O Nanosecond repetitively pulsed discharges in air at atmospheric pressure - the spark regime 2010 Plasma Sources Sci. Technol. 19065015 (10pp)

[9] Ono R, Teramoto Y and Oda T 2010 gas density in a pulsed positive streamer measured using laser shadograph J Phys D.: Appl. Phys. 43345203 (7pp)

[10] Kosarev I N, Aleksandrov N L, Kindysheva S V, Starikovskaia S M and Starikovskii A Yu 2008 Kinetics of ignition of saturated hydrocarbons by nonequilibrium plasma: $\mathrm{CH}_{4}$-containing mixtures Comb. and Flame $\mathbf{1 5 4} 569$

[11] Starikovskaia S M, Allegraud K, Guaitella O, Kosarev I N, Mintusov E I, Pendleton S J, Popov N A, Sagulenko P N, Rousseau A 2010 Surface discharges: possible applications for plasma-assisted 
ignition and electric field measurements Proc. of 48th AIAA Aerospace Sciences Meeting, 4-7 January 2010, Orlando, Florida, AIAA 2010-1587

[12] A. Flitti and S. Pancheshnyi S 2009 Gas heating in fast pulsed discharges in $\mathrm{N}_{2}-\mathrm{O}_{2}$ mixtures Eur. Phys. J. Appl. Phys. 4521001

[13] Aleksandrov N L, Kindusheva S V, Nudnova M M and Starikovskii A Yu 2010 Mechanism of ultrafast heating in a non-equilibrium weakly ionized air discharge plasma in high electric fields $J$. Phys. D: Appl. Phys. 43 255201(19 pp)

[14] Anokhin E M, Starikovskaia S M and Starikovskii A Yu 2004 Energy transfer in hypersonic plasma flow and flow structure control by low temperature nonequilibrium plasma 42nd AIAA Aerospace Sciences Meeting and Exhibit (Reno, NV, 710 January 2004) paper AIAA-2004-674

[15] Popov N A 2010 Fast gas heating in nitrogen-oxygen discharge plasma. I. Kinetic mechanism. $J$. Phys. D: Appl. Phys. (submitted)

[16] Vasilyak L M, Kostyuchenko S V, Kudryavtsev N N and Filyugin I V 1994 High-speed ionization waves at an electric breakdown Phys.-Uspekhi 163263

[17] Starikovskaia S M, Anikin N B, Pancheshnyi S V, Zatsepin D V and Starikovskii A Yu 2001 Pulsed breakdown at high overvoltage: development, propagation and energy branching Plasma Sources Sci. Technol 10344

[18] Anikin N B, Starikovskaia S M and Starikovskii A Yu 1998 The development of high velocity ionization wave in systems with various configuration of high-voltage electrodes High Temperature 36(6) 969

[19] Mintoussov E, Lacoste D A, Pendleton S J, Popov N A, Stancu G D, Laux C O and Starikovskaia S M, Proc. of ESCAMPIG 2010, P1.39

[20] Anikin N B , Starikovskaia S M and Starikovskii A Yu 2002 Polarity effect of applied pulse voltage on the development of uniform nanosecond gas breakdown J. Phys. D: Appl. Phys. 352785

[21] Pancheshnyi S V, Starikovskaia S M and Starikovskii A Yu 1999 Population of nitrogen molecule electron states and structure of the fast ionization wave J. Phys. D: Appl. Phys. 322219

[22] Laux C O 2002 Radiation and nonequilibrium collisional-radiative models in: Physico-Chemical Modeling of High Enthalpy and Plasma Flows (von Karman Institute Lecture Series 2002-07, eds. Fletcher D, Charbonnier J-M, Sarma G S R and Magin T, Rhode-Saint-Genese, Belgium)

[23] Panchesnyi S V, Starikovskaia S M and Starikovskii A Yu 2000 Collisional deactivation of $\mathrm{N}_{2}\left(\mathrm{C}^{3} \Pi_{u}\right.$, $v=0,1,2,3)$ states by $\mathrm{N}_{2}, \mathrm{O}_{2}, \mathrm{H}_{2}$ and $\mathrm{H}_{2} \mathrm{O}$ molecules Chemical Physics 262349

[24] Starikovskaia S M, Kukaev E N, Kuksin A Yu, Nudnova M M and Starikovskii A Yu 2004 Analysis of spatial uniformity of the combustion of a gaseous mixture initiated by a nanosecond discharge Comb. and Flame 139177

[25] Kossyi I A, Kostinsky A Y, Matveev A A and Silakov V P 1992 Kinetic scheme of the nonequilibrium discharge in nitrogen-oxygen mixtures Plasma Sources Sci.Technol.1(3) 207

[26] Popov N A 2010 Evolution of the negative ion composition in the afterglow of a streamer discharge in air Plasma Phys. Rep. 36(9) 828

[27] Hagelaar G J and Pitchford L C 2005 Solving the Boltzmann equation to obtain electron transport coefficients and rate coefficients for fluid models it Plasma Sources Sci. Technol. 14722

[28] Phelps A V and Pitchford L C 1985 Anisotropic scattering of electrons by $\mathrm{N}_{2}$ and its effect on electron transport Phys. Rev. A. 31(5) 2932

[29] Aleksandrov N L and Kochetov I V 1987 Influence of vibrational excitation on rates of electronic processes in weakly ionized plasma of molecular gases and gas mixtures Fizika Plazmy 25(6) 1062 (In Russian)

[30] Herron J T 1999 Evaluated chemical kinetics data for reactions on $\mathrm{N}\left({ }^{2} \mathrm{D}\right), \mathrm{N}\left({ }^{2} \mathrm{P}\right)$, and $\mathrm{N}_{2}\left(\mathrm{~A}^{3} \Sigma_{u}^{+}\right)$ in the gas phase J. Phys. Chem. Ref. Data. 28(5) 1453

[31] Florescu A I and Mitchell J B A 2006 Dissociative recombination Physics Reports 430277

[32] Cao Y S and Johnsen R 1991 Recombination of $\mathrm{N}_{4}^{+}$ions with electrons J. Chem. Phys. 957356

[33] Slovetskii D I 1980 Mechanisms of Chemical Reactions in Nonequilibrium Plasma (Moscow: Nauka) (in Russian) 
[34] Capitelli M, Ferreira C M, Gordiets B F and Osipov A I 2000 Plasma kinetics in atmospheric gases (Springer)

[35] Golde M F and Moyle A M 1985 Study of the products of the reactions of $\mathrm{N}_{2}\left(\mathrm{~A}^{3} \Sigma_{u}^{+}\right)$: the effect of vibrational energy in $\mathrm{N}_{2}\left(\mathrm{~A}^{3} \Sigma_{u}^{+}\right)$Chem. Phys. Lett 117375

[36] Piper L G 1987 Quenching rate coefficients for $\mathrm{N}_{2}\left(\mathrm{a}^{\prime}{ }^{1} \Sigma_{u}^{-}\right)$J. Chem. Phys. 871625

[37] Pancheshnyi S V, Starikovskaia S M and Starikovskii A Yu 2000 Collisional deactivation of $\mathrm{N}_{2}\left(\mathrm{C}^{3} \Pi_{u}, v=0-3\right)$ states by $\mathrm{N}_{2}, \mathrm{O}_{2}, \mathrm{H}_{2}, \mathrm{H}_{2} \mathrm{O}$ molecules Chem. Phys. 262349

[38] Popov N A 2006 Simulation of a longitudinal glow discharge in a hot air flow at atmospheric pressure Plasma Phys. Rep. 32237

[39] Aleksandrov N L, Dyatko N A and Kochetov I V 1995 Rate of inelastic electron processes in a weakly ionized plasma in a nonstationary electric field Plasma Physics Reports 21(9) 763 